\title{
ARM Climate Research Facility Spectral Surface Albedo Value-Added Product (VAP) Report
}

\author{
S McFarlane \\ K Gaustad \\ C Long \\ E Mlawer
}

July 2011

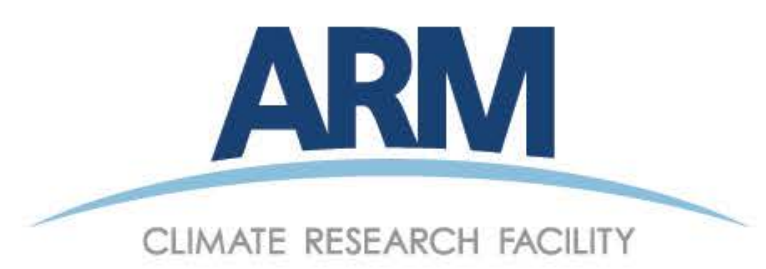




\section{DISCLAIMER}

This report was prepared as an account of work sponsored by the U.S. Government. Neither the United States nor any agency thereof, nor any of their employees, makes any warranty, express or implied, or assumes any legal liability or responsibility for the accuracy, completeness, or usefulness of any information, apparatus, product, or process disclosed, or represents that its use would not infringe privately owned rights. Reference herein to any specific commercial product, process, or service by trade name, trademark, manufacturer, or otherwise, does not necessarily constitute or imply its endorsement, recommendation, or favoring by the U.S. Government or any agency thereof. The views and opinions of authors expressed herein do not necessarily state or reflect those of the U.S. Government or any agency thereof. 


\title{
ARM Climate Research Facility Spectral Surface Albedo Value- Added Product (VAP) Report
}

\author{
S McFarlane \\ K Gaustad \\ C Long \\ E Mlawer
}

July 2011

Work supported by the U.S. Department of Energy,

Office of Science, Office of Biological and Environmental Research 


\section{Contents}

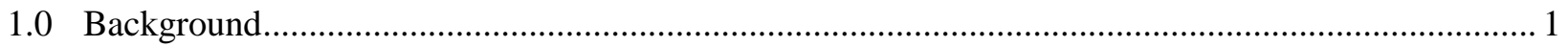

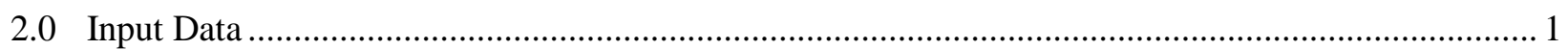

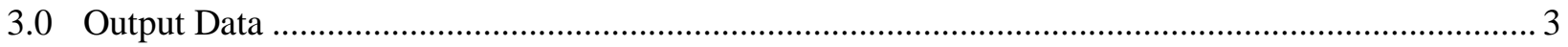

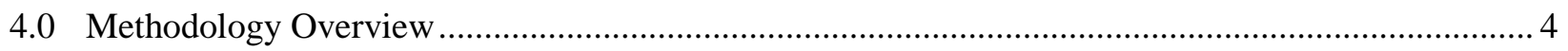

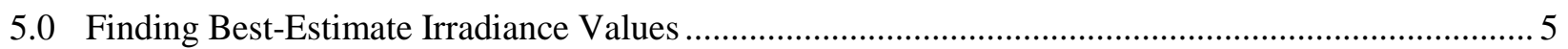

5.1 Finding Best-Estimate Downwelling Broadband ......................................................... 6

5.2 Finding Best-Estimate Downwelling Narrowband .............................................................. 10

5.3 Estimating Bad and Missing Downwelling Irradiance Data .................................................. 13

5.4 Finding Best-Estimate Upwelling Broadband and Narrowband ............................................. 14

5.5 Calculating Broadband and Narrowband Albedo ................................................................ 17

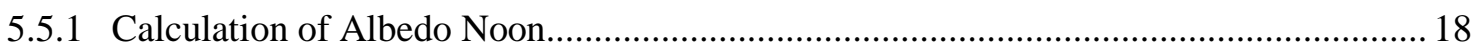

5.5.2 Calculation of 'Direct' Albedo Slope and Offset ........................................................... 19

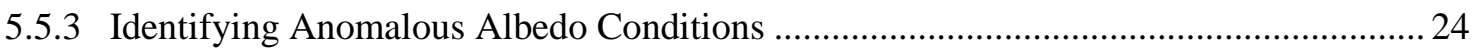

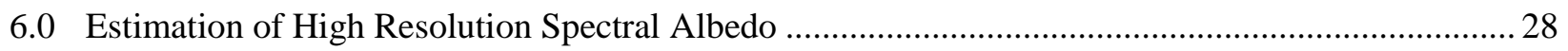

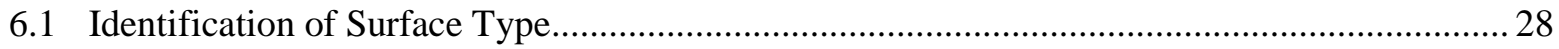

6.2 Estimation of High Resolution Spectral Albedo .................................................................... 31

6.3 Comparison to Broadband Albedo Measurements ....................................................................... 33

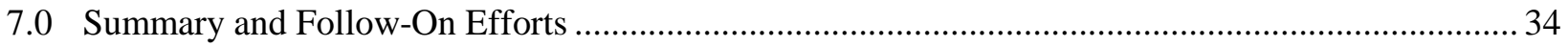

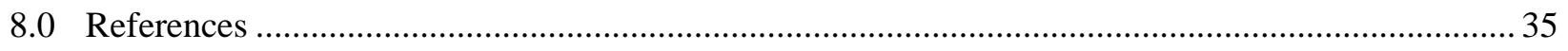

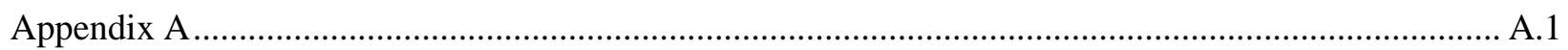

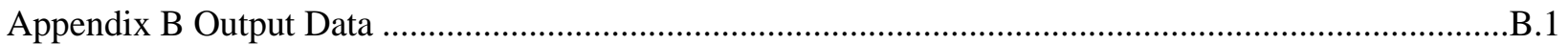




\subsection{Background}

This document describes the input requirements, output data products, and methodology for the Spectral Surface Albedo (SURFSPECALB) value-added product (VAP). The SURFSPECALB VAP produces a best-estimate near-continuous high spectral resolution albedo data product using measurements from multifilter radiometers (MFRs). The VAP first identifies best estimates for the MFR downwelling and upwelling shortwave irradiance values, and then calculates narrowband spectral albedo from these bestestimate irradiance values. The methodology for finding the best-estimate values is based on a simple process of screening suspect data and backfilling screened and missing data with estimated values when possible. The resulting best-estimate MFR narrowband spectral albedos are used to determine a daily surface type (snow, 100\% vegetation, partial vegetation, or $0 \%$ vegetation). For non-snow surfaces, a piecewise continuous function is used to estimate a high spectral resolution albedo at 1 min temporal and $10 \mathrm{~cm}^{-1}$ spectral resolution.

The SURFSPECALB VAP was developed for use as input to a planned Short Wave Quality Metric Experiment (SWQME) project. The SWQME is designed to assess understanding of shortwave spectral radiative transfer by comparing output from the Code for High resolution Accelerated Radiative Transfer and Scattering (CHARTs) radiative transfer model (Clough et al. 2005) to spectral radiation measurements from the rotating shadowband spectroradiometer (RSS; Kiedron et al. 2006) and shortwave spectroradiometer (SWS; Pilewskie and Pommier 2007) instruments. Aside from this specific application, high-resolution surface albedo products are also needed by the atmospheric science community to run high spectral resolution radiative transfer models and to calculate broadband albedos across specific wavelength ranges for running broadband radiative transfer models (such as for the broadband heating rate profiles [BBHRP] VAP). The irradiance and surface albedo products produced by the SURFSPECALB VAP could also be useful to the atmospheric science community for validating solar radiation models for solar energy systems and to the remote sensing community.

\subsection{Input Data}

Broadband and narrowband shortwave surface albedo values are derived from the ratio of upwelling to downwelling radiometric measurements. Spectral radiometric instrumentation at the Atmospheric Radiation Measurement (ARM) facilities include multifilter rotating shadowband radiometers (MFRSRs) positioned facing upward to measure downwelling irradiance and multifilter radiometers (MFRs) positioned facing downward to measure upwelling irradiance. The MFRs and MFRSRs measure spectral irradiance using 10-nm-wide filters centered at $415 \mathrm{~nm}, 500 \mathrm{~nm}, 615 \mathrm{~nm}, 870 \mathrm{~nm}$, and $940 \mathrm{~nm}$ and also measure an un-calibrated broadband shortwave irradiance using an "open” channel. The MFRSR has a rotating shadowband, which periodically shades the instrument, allowing measurement of both diffuse and total downwelling shortwave irradiance (direct shortwave irradiance is derived from the difference of the diffuse and total). As all irradiance measurements used in the VAP are shortwave irradiances, we hereafter refer to them as either narrowband or broadband irradiances, and drop the "shortwave" identification.

At this time the VAP only runs at the Southern Great Plains (SGP) site, although extension to the North Slope of Alaska (NSA) is planned in the future. At the SGP Central Facility, there are two collocated 
MFRSRs (at the C1 and E13 facilities), which provide redundant downwelling broadband and narrowband measurements (hereafter referred to as MFRSRC1_BB, MFRSRC1_NB, MFRSRE13_BB, and MFRSE13_NB). There are also two downward-looking MFRs at the SGP central facility. These are geographically separated by approximately $300 \mathrm{~m}$, with one located on the SMOS 10-m tower above an un-mowed pasture and another at the 25-m level of the 60-m tower above a cultivated field (hereafter referred to as MFR10M and MFR25M, respectively). The 10-m wild grass and 25-m crop surfaces are representative of the surface types near the SGP Central Facility, although they do not cover the entire range of surfaces seen in the area. While it is theorized that the values from these two sites can be weighted to represent the larger area, the SURFSPECALB VAP produces individual albedo products for the $10-\mathrm{m}$ and $25-\mathrm{m}$ tower locations, so that users can choose their own areal weightings.

The MFRSR, 10-m MFR, and 25-m MFR measurements used by the SURFSPECALB VAP are retrieved from the following ARM datastreams:

- SSSmfrsrFF.b1

- SSSmfr10mFF.b1

- SSSmfr25mFF.b1

Where

SSS - refers to the site

FF - refers to the facility

The variables in these datastreams correlating to MFRSRC1_BB, MFRSRC1_NB, MFRSRE13_BB, MFRSRE13_NB, MFR10M, and MFR25M are described in Appendix A. At this time the VAP is limited to the SGP and its C1 and E13 facilities.

The identification of best-estimate irradiance values at the SGP was facilitated through the use of two supplemental broadband irradiance ARM data products. The best-estimate flux (BEFLUX) VAP (Shi and Long 2002) combines measurements from three collocated radiometer systems at the SGP Central Facility to produce a best estimate of broadband downwelling and upwelling shortwave irradiance (hereafter referred to as BEFlux_DOWN and BEFlux_UP). Additionally, broadband upwelling irradiance measured by a calibrated pyranometer located on the 25-m tower (PSP25M) provides an additional point of reference for assessing upwelling MFR irradiance.

The BEFlux1Long and PSP irradiance values are located in the following ARM datastreams:

- SSSbeflux1longFF.c1

- SSSirt25FF.b1

Where

SSS - refers to the site

$\mathrm{FF}$ - refers to the facility 
The variables in these datastreams correlating to BEFlux_DOWN, BEFlux_UP, and PSP25M are described in Appendix A. For these datastreams the VAP currently runs only at the SGP site and C1 facility.

\subsection{Output Data}

The VAP produces two output files:

sgpsurfspecalb1mlawerC1.c1.YYMMDD.hhmmss,

and

sgpsurfspecalb1mlawerC1.s1.YYMMDD.hhmmss

where:

- SGP is the site at which the VAP is run

- surfspecalb is the name of the VAP

- 1Mlawer identifies that this is version 1 of Mlawer's algorithm

- $\mathrm{C} 1$ is the facility

- YYYY is the year, MM the month, DD the day, hh the hour, mm the minute, and ss the second of the data start

- c1 indicates the base level output of the VAP and s1 indicates a summary file

The output data are on 60-s temporal resolution. The .c1 level output file includes:

- all of the gridded 60-s irradiance values from the surface, 10-m tower, and 25-m tower instruments and their bit-packed quality control (qc) flags

- the best-estimate values of all of the MFR and MFRSR broadband and narrowband irradiances and their qc and status flags

- the best-estimate broadband and narrowband surface albedos and their qc flags

- the estimated surface type and high spectral resolution albedo and their qc flags at each tower

- the broadband albedo calculated from integrating the spectral albedo at each tower.

In addition to the .c1 datastream, the VAP also produces an .s1 datastream that consists of only the bestestimate irradiances and albedos, spectral albedo measurements, and surface types and reports QC using a simple four-state representation of good, bad, indeterminate, or missing. A detailed list of the variables included in the .c1 and .s1 datastreams are listed in Appendix B.

The VAP produces three classes of quicklook plots consisting of (1) the broadband irradiance, broadband, and narrowband albedos, (2) the extrapolated spectral albedo for the sample closest to solar noon, (3) comparison plots of the global albedo resulting from an integration of the extrapolated spectral albedo 
to the PSP albedo and (4) comparison of integrated albedo to the best-estimate albedo. A total of seven plots are produced for the SGP, as some plots are created for the 10-m and 25-m towers separately. The quicklook plots created and a brief description of their content is listed below:

Table 1. Daily quicklook plots produced by the VAP.

\begin{tabular}{|c|c|}
\hline $\begin{array}{c}\text { Quicklook File name } \\
\text { (TT = 10m or 25m) }\end{array}$ & Description \\
\hline $\begin{array}{c}\text { sgpsurfspecalb1mlawerC1.c1. } \\
\text { YYYYMMDD.000000.mfrTT_albedo.png }\end{array}$ & $\begin{array}{l}\bullet \quad \text { broadband irradiance vs. julian day } \\
\text { albedo vs. julian day } \\
\text { broadband albedo vs. cosZ }\end{array}$ \\
\hline $\begin{array}{c}\text { sgpsurfspecalb1mlawerC1. } \\
\text { YYYYMMDD.000000.spectral_albedo.png }\end{array}$ & $\begin{array}{c}\text { spectral albedo vs. wavelength for 10m } \\
\text { and 25m towers }\end{array}$ \\
\hline sgpsurfspecalb1mlawerC1. & $\begin{array}{c}\text { psp and integrated spectral albedo vs } \\
\text { julian day }\end{array}$ \\
\hline YYYYMMDD.000000.psp_bb_alb_from_spec_TT.png & $\begin{array}{c}\text { best estimate and integrated spectral } \\
\text { albedo vs julian day }\end{array}$ \\
\hline Sgpsurfspecalb1mlawerC1. &
\end{tabular}

\subsection{Methodology Overview}

The SFCSPECALB VAP has two main components. The first part of the VAP develops a best estimate of the narrowband spectral albedo for each tower containing an MFR (the 10-m and 25-m towers at SGP). In the second part of the VAP, these best-estimate values are used to estimate the surface type (soil, vegetation, partial vegetation, or snow) and then to produce a high-resolution spectral albedo that is consistent with both the estimated surface type and the best-estimate narrowband albedo values.

A flow chart of the overall SURFSPECALB logic is shown in Figure 1. More details of each of the component pieces of the VAP are given in the next sections. Since one aim of the VAP is to produce a continuous data product, the VAP processes a month of data at a time, so that data from surrounding days can be used to fill in missing data. Multiple loops over the data are performed, as various values are calculated sequentially based on the best estimates created in the previous step.

In the initial loop, best-estimate irradiance values and surface albedo at the MFR wavelengths are determined for each day of the month. After the irradiance and surface albedo values have been determined for each day, the VAP again loops across each day of the month and calculates the near-noon albedo value, and then performs another loop to find the direct and diffuse albedo for each day (see Section 5.5). A final loop across each day in the month is performed to estimate MFR albedo values for missing and bad samples (using the near-noon and direct and diffuse albedo values), determine the surface type, and produce the high spectral resolution albedo. Quality control and status flags are included on each of the best-estimate values, as described in more detail in the next sections, and qc flags are also included on the final estimated spectral albedo values. 


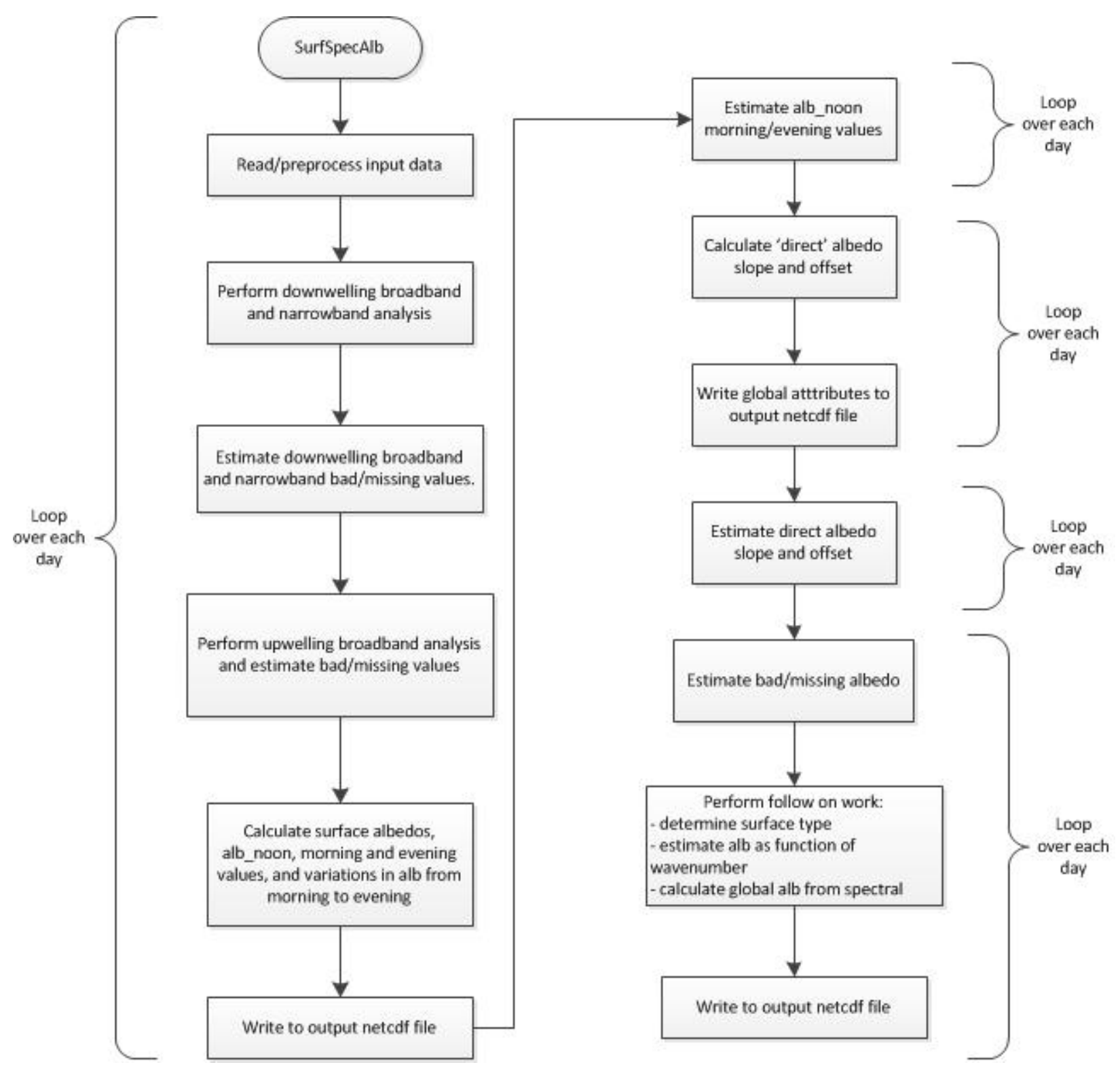

Figure 1. Flow chart of SURFSPECALB best-estimate and albedo calculation methodologies.

\subsection{Finding Best-Estimate Irradiance Values}

The first step in finding best-estimate irradiance values is to identify and remove suspect values in the MFR irradiances, and, where possible, fill in missing or bad values with estimated values to produce a near-continuous data set. Bad or suspect values are found through inter-comparisons with similar measurement values and application of limit tests. To estimate values for missing/bad data, the general approach is to develop relationships between the narrowband to broadband upwelling irradiance values for good data periods and then use those relationships to estimate values when one of the parameters is missing or bad. In general, the broadband values are more reliable (largely because there are more broadband measurements available increasing redundancy), and so broadband irradiances are evaluated first and then used in the analysis of the narrowband irradiance values. 
Preprocessing of the input data is performed to create common sampling periods and to apply more rigorous and uniform qc checks. All irradiance values are put on a common 60s time grid. To address the tendency of data loggers to drift with time, and to remove small errors, irradiances are averaged over a 5 minute moving window. Gaps in the input data are filled with missing values to create a set of regularly gridded data that spans the entire day. Additionally, the MFRSR downwelling broadband irradiance values are calibrated by scaling them to the downwelling broadband irradiance values from the BEFlux1Long datastream. This calibration is performed by calculating the slope of the best-fit line between the BEFlux1Long versus the MFRSR values over the given day.

The approach for identifying and assigning quality to suspect irradiance samples is primarily driven by the availability of similar collocated measurements and is fundamentally the same for all irradiance measurements. The screening process for identifying bad and missing downwelling broadband irradiance samples and assigning a quality for downwelling broadband irradiance is described first, followed by a description of the general approach used to backfill the bad and missing samples with estimated values to produce the best-estimate product. Individual descriptions of the process for identifying and removing suspect values for the downwelling narrowband, upwelling broadband, and upwelling narrowband irradiances are then presented.

\subsection{Finding Best-Estimate Downwelling Broadband}

At the SGP, a best-estimate downwelling broadband irradiance value (hereafter referred to as MFRSR_BB) is derived from the pre-processed MFRSRC1_BB and MFRSRE13_BB datastreams by comparing the values to each other and to the BEFlux_DOWN value. Limits for the ratio tests used in these comparisons were determined by analysis of multiple years of data; narrower limits can be applied to the inter-MFRSR tests, while slightly broader limits are used for the MFRSR to BEFlux1Long comparison. When possible, the average of the MFRSRC1_BB and MFRSRE13_BB data sets is the preferred best-estimate value, but if one of these datastreams is missing or bad, the other will be used as the best-estimate value.

During overcast periods, defined as the BEFlux_DOWN being less than $200 \mathrm{~W} / \mathrm{m} \wedge 2$, small irradiance values skew the ratio tests, making it difficult to accurately estimate broadband albedo. During these periods, only the ratio test of each of the downwelling broadband MFRSR irradiances to BEFlux_DOWN is performed.

A flowchart of the logic employed to determine the best-estimate broadband value is given in Figure 2. In this figure, BB_C1, BB_E13, and BE represent the MFRSRC1_BB, MFRSR_E13, and BEFlux_DOWN datastreams, respectively, and BB is the final best-estimate broadband value. The flow chart also shows the QC determination applied at each step in the process. 


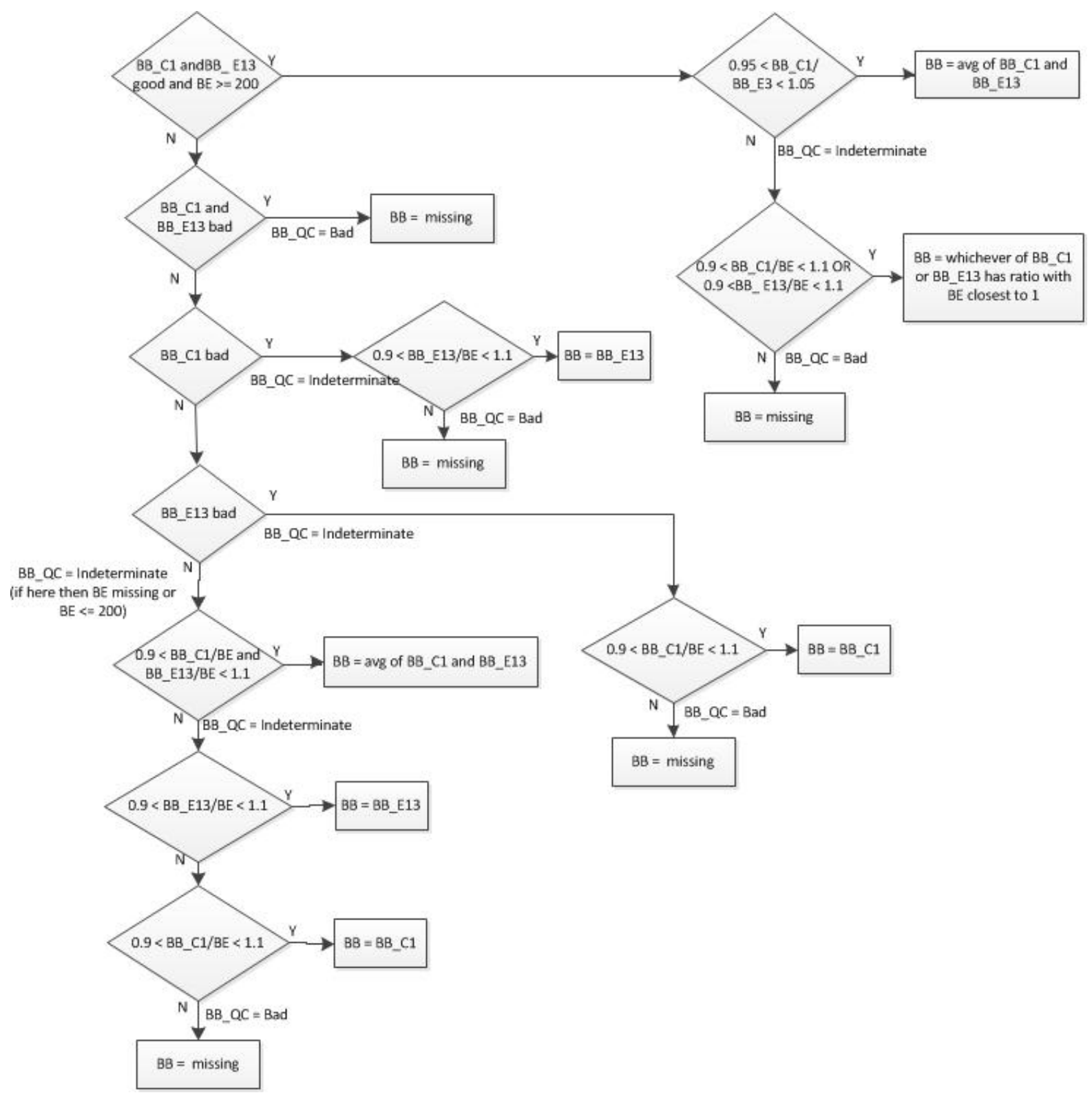

Figure 2. Logic used to derive downwelling broadband best-estimate values.

The next three figures show examples of the downwelling broadband analysis for days with mostly clear skies (Figure 3), overcast clouds (Figure 4) and broken cloudiness (Figure 5).

In the clear-sky example (Figure 3), for most of the day (except near sunset), the ratio of the two MFRSR values falls within the desired range, samples pass the $200 \mathrm{~W} / \mathrm{m}^{\wedge} 2$ limit, and the best-estimate downwelling broadband irradiance is the average of the two MFRSR values. Near sunset, the MFRSRC1 diverges from the other two instruments, and hence the E13 instrument is chosen as the best value during this time. 


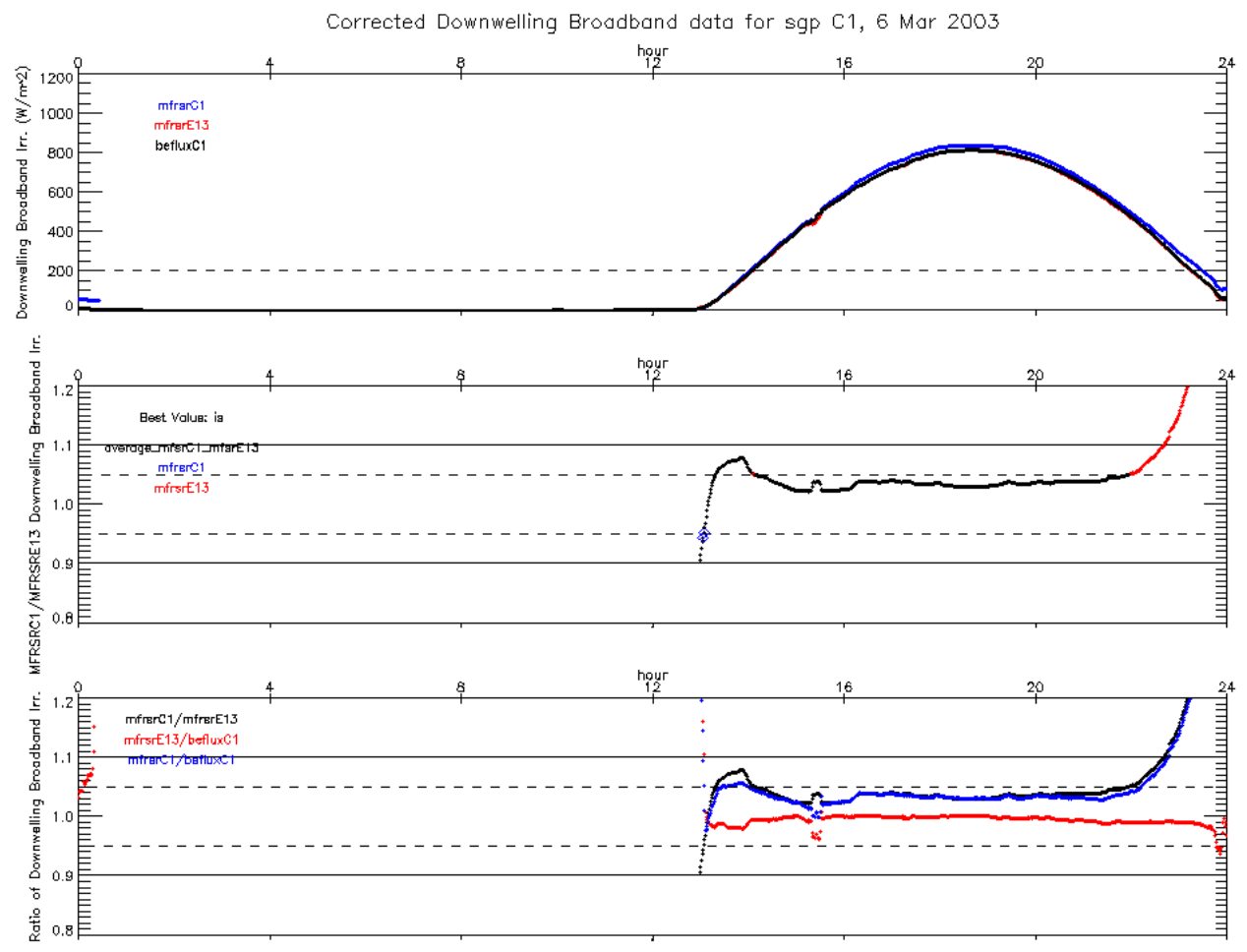

Figure 3. Broadband analysis for a clear day (March 6, 2003). Panels show (top) broadband irradiance for each instrument, (middle) ratio test used to identify preferred downwelling global value as well as the facility/instrument identified as 'best' at each time, and (bottom) ratio tests used in evaluation of data.

During an overcast day (Figure 4), there are few periods for which the downwelling broadband is greater than $200 \mathrm{~W} / \mathrm{m}^{\wedge} 2$, but for the most part the two MFRSR values are well correlated, so the average of the two instruments is the best estimate for most of the day. There are a few periods where MFRSRE13, which is generally higher than MFRSRC1, is outside of the limits of the ratio test to BEFLUX, so the best-estimate value is MFRSRC1 during those periods.

During transitions from clear to overcast during broken cloudiness conditions, the ratio of the two MFRSR values is frequently outside of the $5 \%$ limit, and overcast cross-instrument ratio tests must be applied to determine the best-estimate downwelling irradiance. Figure 5 is an example of a day with several of these transition periods as illustrated by the blue and red points in the middle panel that represent ratio tests of MFRSRC1 and MFRSRE13 to the BEFlux1long irradiance values. During these transition periods, MFRSRC1 (blue points) or MFRSRE13 (red points) were selected as the best MFRSR broadband value, rather than the average of the two values (black). 


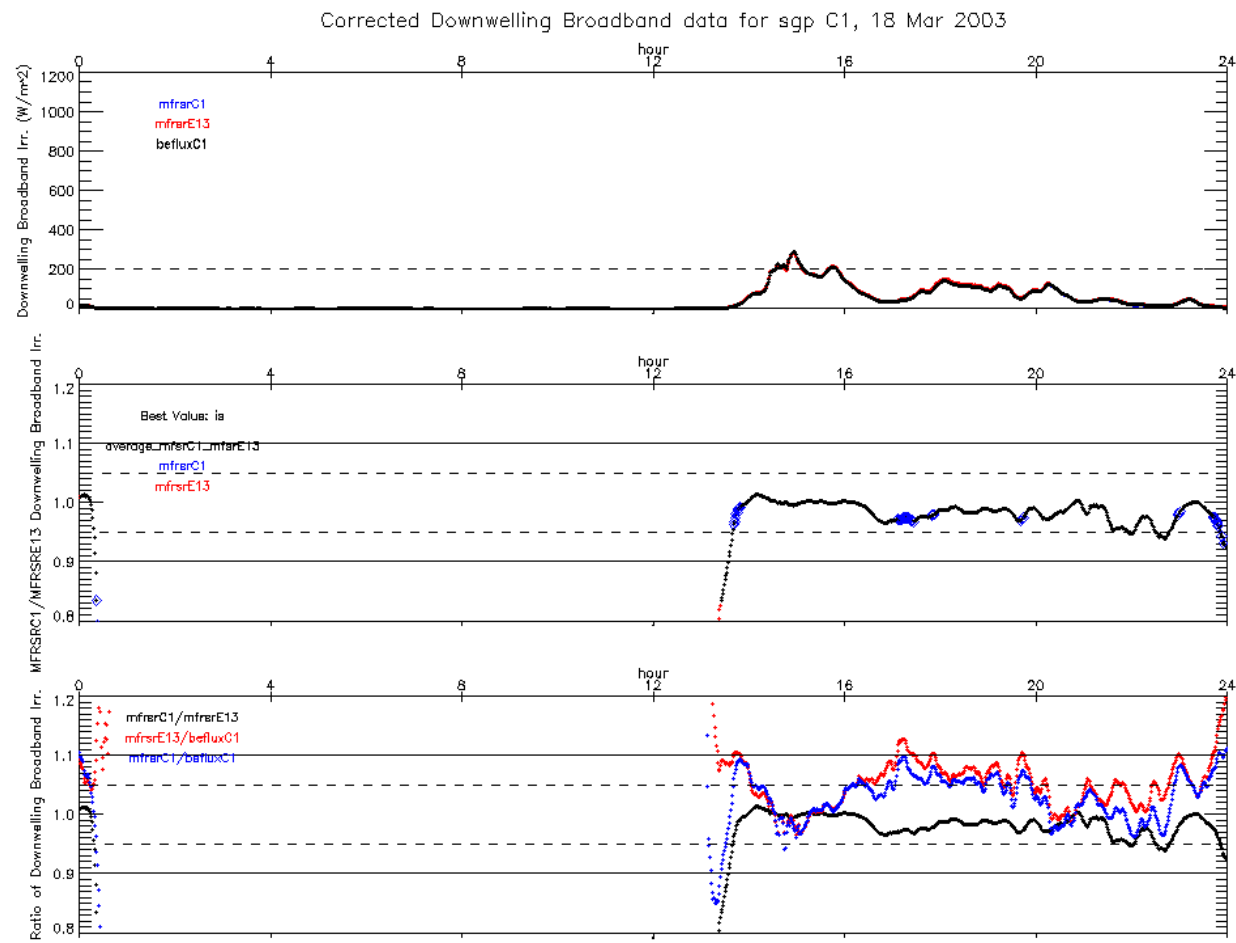

Figure 4. As in Figure 3 but for an overcast day (March 18, 2003) at SGP.

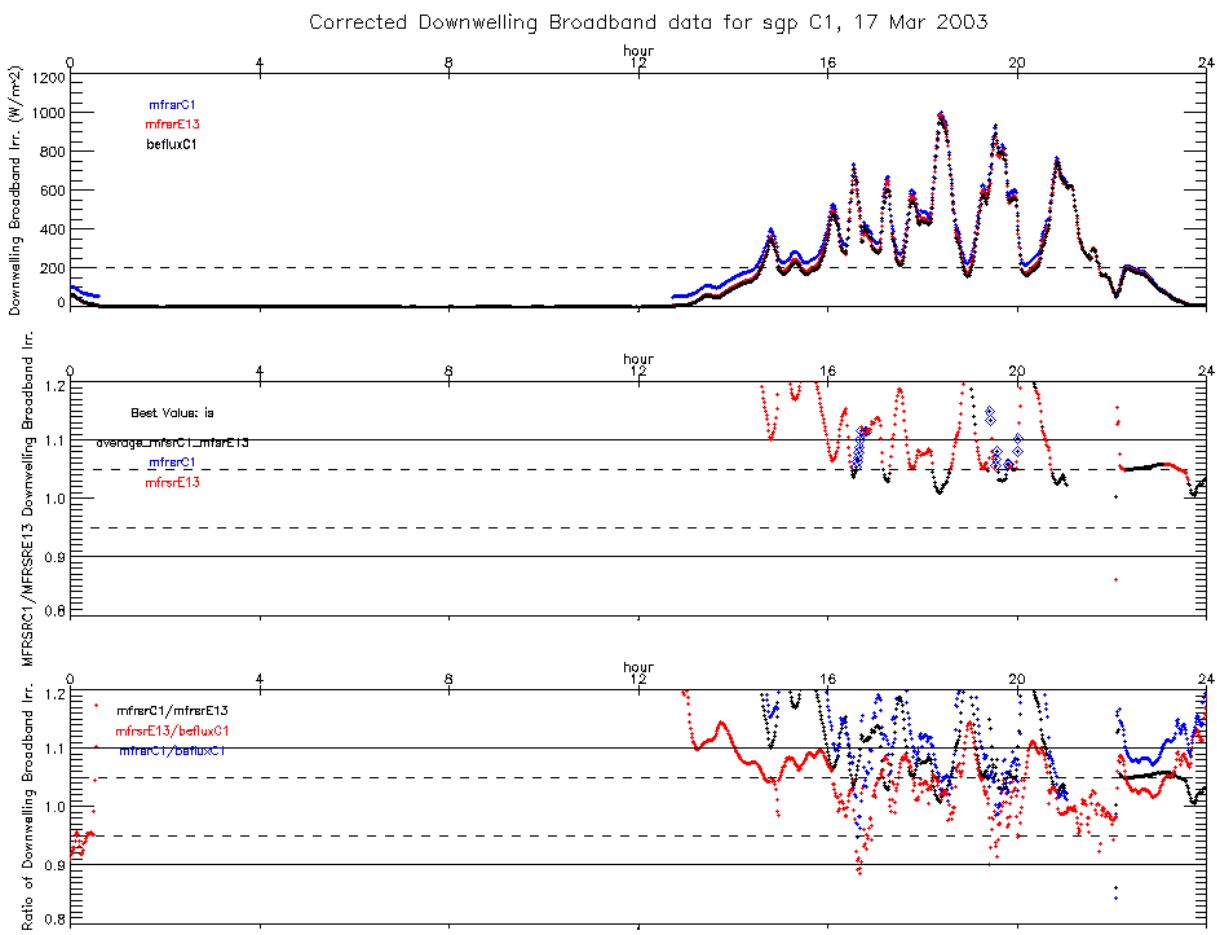

Figure 5. As in Figure 3, but for a day with broken cloudiness conditions at SGP (March 17, 2003). 


\subsection{Finding Best-Estimate Downwelling Narrowband}

Because the broadband measurement does not use a filter (which may drift with time) and because the broadband values can be more directly compared to coincident measurements (from the other radiometer systems), the broadband measurement is more robust than the narrowband measurement. Therefore, we assume that if an MFRSR broadband sample is suspect or bad, then the corresponding MFRSR downwelling narrowband spectral measurements are also suspect. The analysis of the broadband values play a role in flagging suspect and bad narrowband downwelling irradiances and in estimating narrowband irradiance values for samples found to be missing or bad (as discussed in the next section).

For the narrowband downwelling irradiances, only the two collocated MFRSRC1_NB and MFRSRE13_NB measurements are available for analysis. Because it is difficult to determine a best downwelling narrowband value (BEMFRSR_NB) with only two measurements to compare, we use the information previously gained from the downwelling broadband analysis in the downwelling narrowband analysis. Periods of cross-instrument disagreement are screened through a process of applying limits to the ratio of the two MFRSR narrowband measurements. For the narrowband case, the limit applied is broadened for the inter-instrument test to the range 0.9 to 1.1 .

An overview of the narrowband logic applied and QC flags set is presented in Figure 6 below. In the flow chart below, BE is the downwelling broadband value from the BEFlux1long data set, BB is the bestestimate broadband value derived previously (Section 5.1), and NB is the output best-estimate value. The logic is applied to each of the individual MFR channels independently.

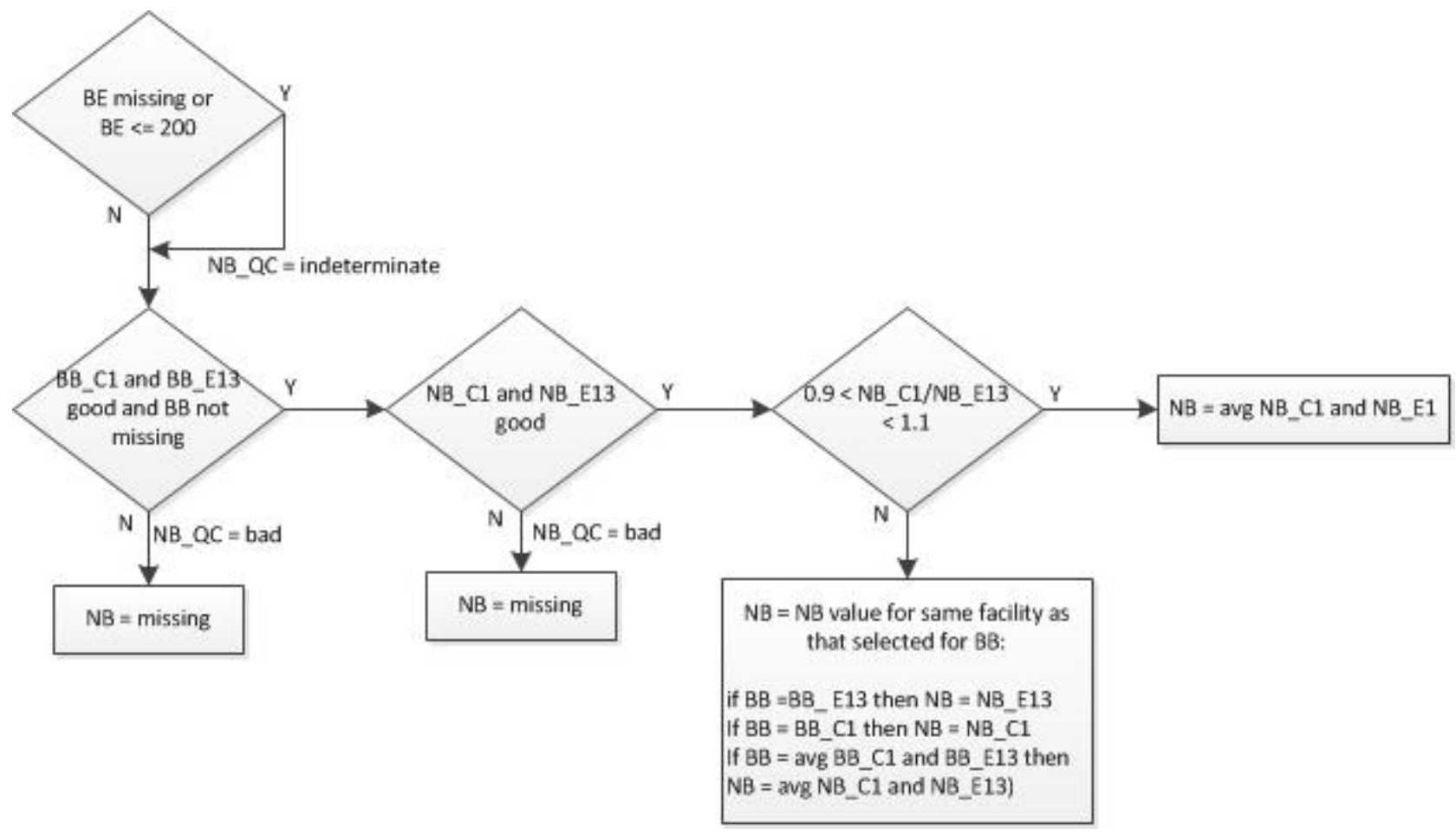

Figure 6. Logic for calculation of downwelling narrowband best estimate. 
BEMFRSR_NB is set equal to MFRSR_NB, and missing and bad samples are replaced wherever possible using estimations based on the ratio of the known good MFRSR_NB to BEMFRSR_BB, as described in Section 5.2.

Plots of the ratio of the narrowband irradiance between the two facilities reveal that the narrowband ratios are often not as well behaved as the broadband MFRSR ratios for the same day. In Figure 7 (bottom panel), which shows a clear day, narrowband ratios of MFRSRC1 to MFRSRE13 can be seen to be much broader than in the same broadband ratio plots shown in Figure 3. In particular, the ratio of the 499-nm channels is consistently outside the ratio limits, and it also exhibits temporally varying behavior between 18-22 UTC that is not seen in the other channels.

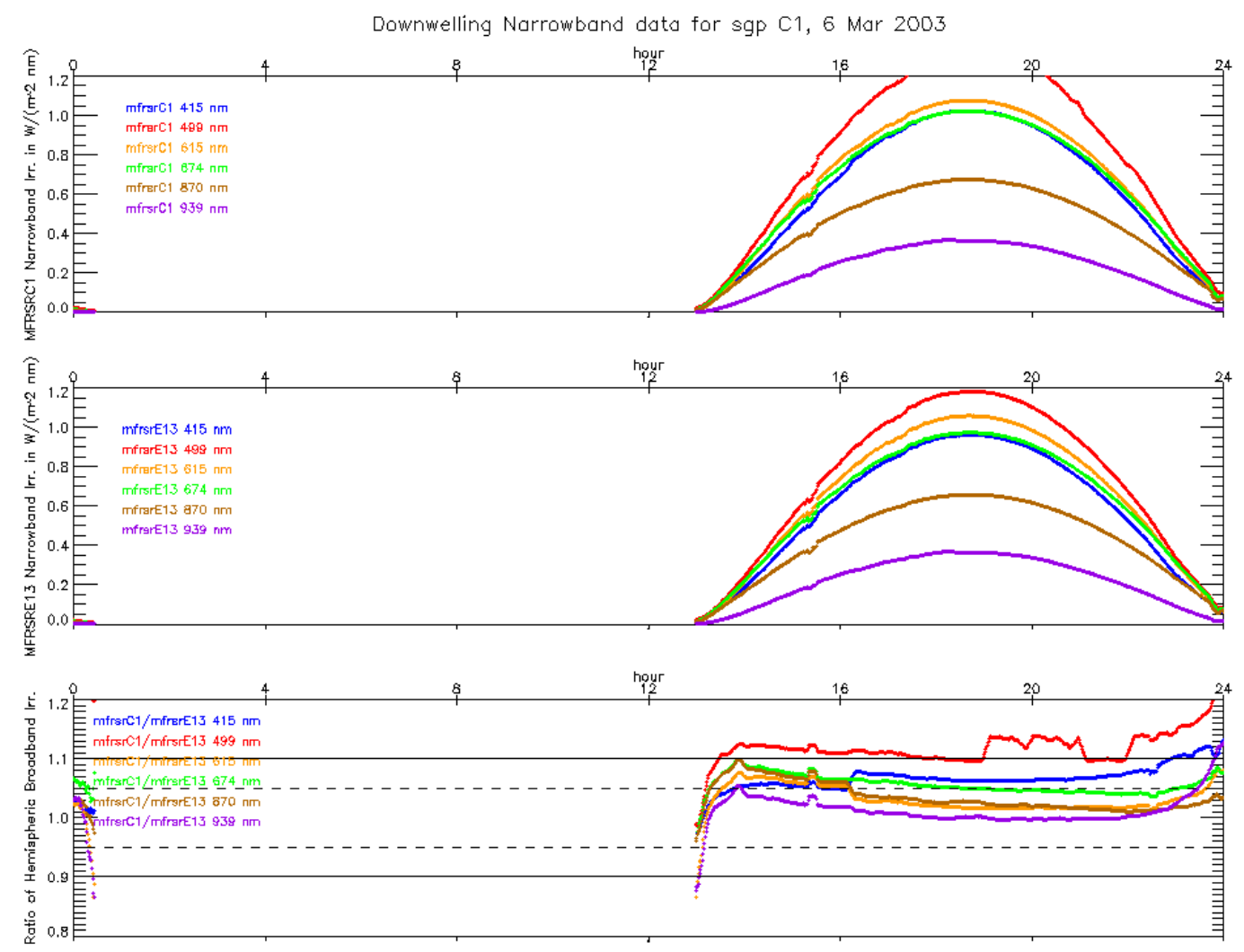

Figure 7. Example of a clear day: (top) spectral irradiance for mfrsrC1, (middle) spectral irradiance for mfrsrE13, and (bottom) ratio tests between filters.

The narrowband irradiance values, ratio tests, and corrections for an overcast day and partly cloudy conditions are shown in Figure 8 and Figure 9 respectively. The consistently high ratios of the 499-nm channel may indicate a problem with the filter in one of the instruments during this period. 
Downwelling Narrowband data for sgp C1, 18 Mar 2003
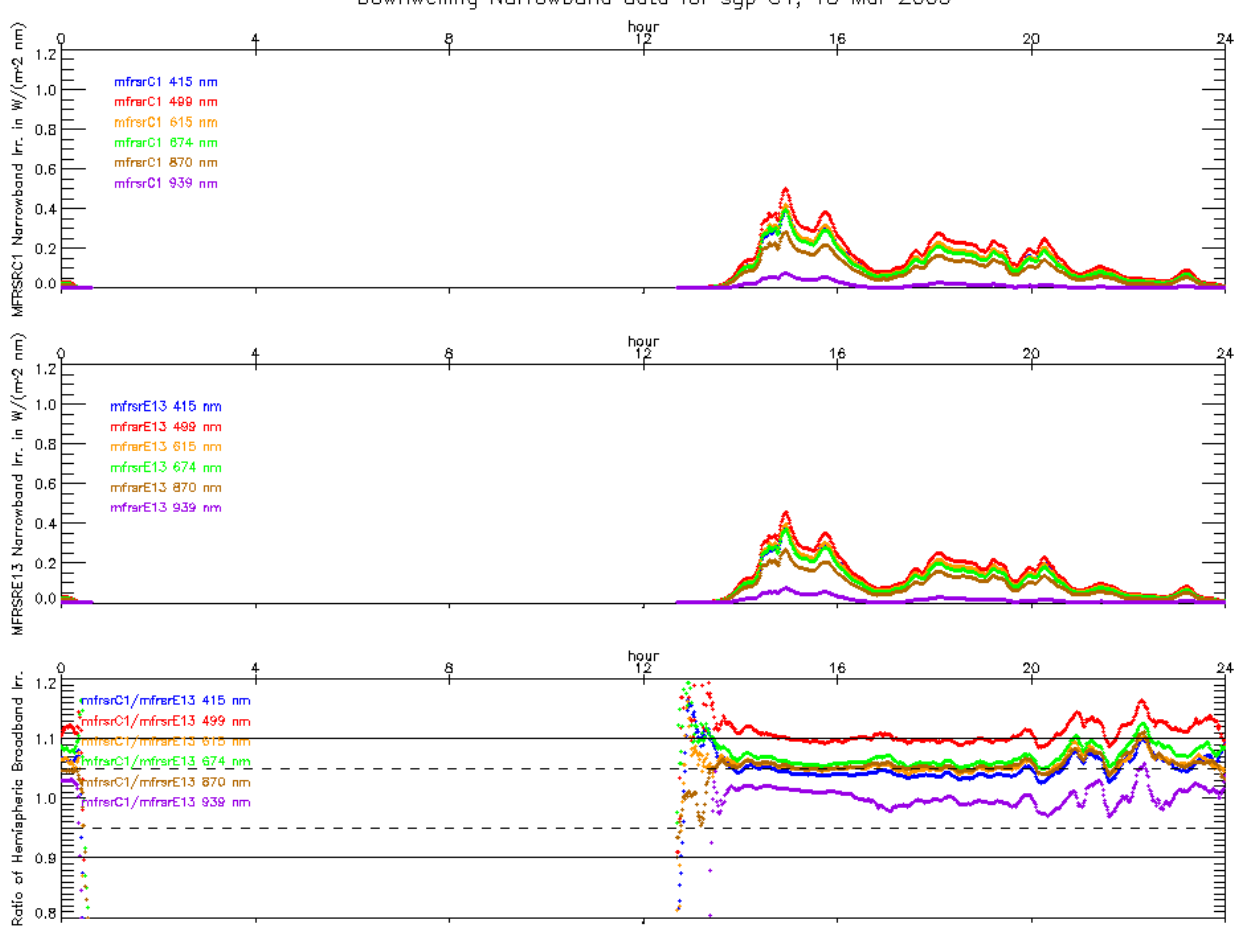

Figure 8. As in Figure 7, but for an overcast day.

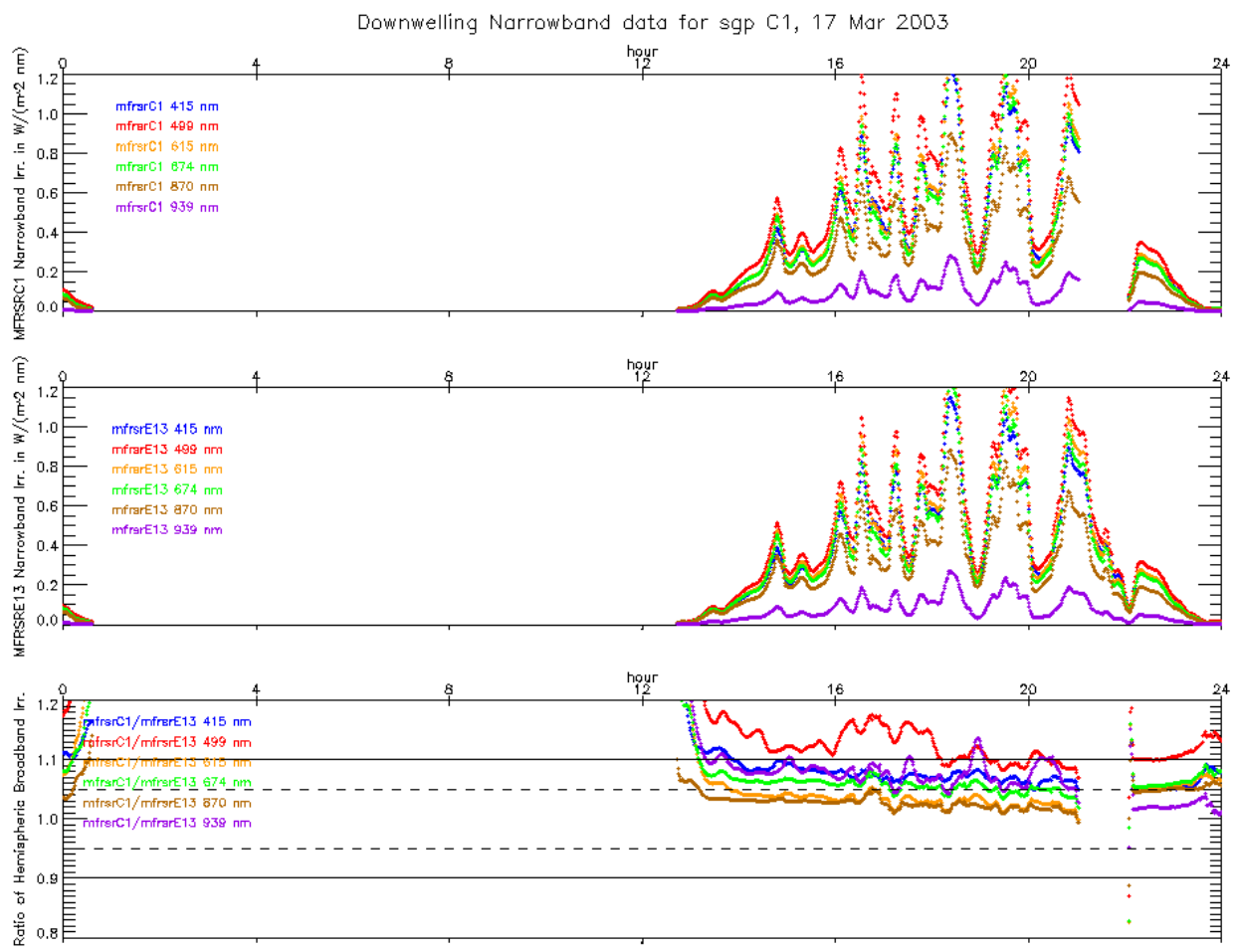

Figure 9. As in Figure 7, but for a day with broken clouds. 


\subsection{Estimating Bad and Missing Downwelling Irradiance Data}

Having screened and flagged the downwelling broadband and narrowband irradiance measurement outliers, missing irradiance values are filled in where possible. The irradiance measurements that precede and follow samples flagged as bad are analyzed to determine the expected ratio of the flagged irradiance to a known good reference value. For each sample identified as missing or bad, the expected ratio multiplied by the known good reference value is used to estimate the missing/bad values.

To prevent poor irradiance estimations the following criteria are applied:

- Data are considered 'bad' and candidates for improvement if the qc value associated with the data has a non-zero value.

- If considered bad, a sample will not be a candidate for correction if, for the sample in question, a flag is set indicating it should not be corrected. Situations where bad data are not corrected are discussed below.

- Data will not be corrected if the amount of continuous bad data is greater than 30 minutes.

- The end of a period of 'bad' data is defined by the occurrence of 5 or more minutes (i.e., samples) of good data. These data can occur either before or after the period of bad data. The search for 'good' data is limited to the current day.

- There must be a sufficient number of 'good' samples occurring either before or after the bad period, or a correction is not attempted. For bad/missing data periods of 5 minutes or less, there must be at least 5 minutes of good data either preceding or following the bad period. If the period of $\mathrm{bad} / \mathrm{missing}$ data is greater than 5 minutes, there must be at least the same number of good samples before or after the bad period as there were bad samples. If the good data occur both before and after the bad period, then we use both sets of good data. Otherwise we use only the leading or trailing good values.

- If fewer than 5 minutes of good data are found when attempting to define the end of a bad period, the good samples are considered bad and added to the total count of bad samples. The appropriate qc fields for these samples are updated to reflect the failure of this requirement. The identification of the end of the bad period will continue until it is found or $>30$ minutes of data are tested. If a bad period is found to be $>30$ minutes, then the data are looped over until the end of the current bad period is found, after which the search resumes for the next bad period.

- Estimations are not made for any sample for which the downwelling broadband irradiance from the BeFlux1Long VAP is $<200 \mathrm{~W} / \mathrm{m}^{\wedge} 2$ or missing.

Once these data sets have been screened, missing/bad values are filled in as described above. However, the ARM datastream from which the known good reference value originates varies according to the type of irradiance to be estimated, as given in Table 2.

For each type of best-estimate irradiance (broadband, narrowband, upwelling, and downwelling), a status flag in the output file indicates whether the irradiance is measured or estimated. 
Table 2. Irradiance values to be estimated and associated reference values used for estimation.

\begin{tabular}{|l|l|}
\hline \multicolumn{1}{|c|}{ Irradiance Value to be Estimated } & \multicolumn{1}{c|}{ Reference Value used in Ratio } \\
\hline $\begin{array}{l}\text { best-estimate downwelling broadband irradiance } \\
\text { (BEMFRSR_BB) }\end{array}$ & $\begin{array}{l}\text { BeFlux1LongC1 downwelling broadband irradiance } \\
\text { (BEFlux_DOWN) }\end{array}$ \\
\hline $\begin{array}{l}\text { best-estimate downwelling narrowband irradiance } \\
\text { (BEMFRSR_NB) }\end{array}$ & $\begin{array}{l}\text { Best-estimate downwelling broadband irradiance } \\
\text { (BEMFRSR_BB) }\end{array}$ \\
\hline $\begin{array}{l}\text { best-estimate MFR10M upwelling broadband } \\
\text { irradiance (BEMFR10M_BB) }\end{array}$ & $\begin{array}{l}\text { BeFlux1LongC1 upwelling broadband irradiance } \\
\text { (BEFlux_UP) }\end{array}$ \\
\hline $\begin{array}{l}\text { best-estimate MFR10M upwelling narrowband } \\
\text { irradiance (BEMFR10M_NB) }\end{array}$ & $\begin{array}{l}\text { Best-estimate MFR10M upwelling broadband } \\
\text { irradiance (BEMFR10M_BB) }\end{array}$ \\
\hline $\begin{array}{l}\text { best-estimate MFR25M upwelling broadband } \\
\text { irradiance (BEMFR25M_BB) }\end{array}$ & $\begin{array}{l}\text { 25-m tower pyranometer upwelling broadband } \\
\text { irradiance (PSP25M) }\end{array}$ \\
\hline $\begin{array}{l}\text { best-estimate MFR25M upwelling narrowband } \\
\text { irradiance (BEMFR25M_NB) }\end{array}$ & $\begin{array}{l}\text { Best-estimate MFR25M upwelling broadband } \\
\text { irradiance (BEMFR25M_BB) }\end{array}$ \\
\hline
\end{tabular}

\subsection{Finding Best-Estimate Upwelling Broadband and Narrowband}

Unlike the downwelling irradiance measurements derived from the collocated MFRSR instrumentation, the MFR instruments at the SGP site are geographically separated. Therefore, best-estimate upwelling broadband and narrowband irradiances for the 10-m and 25-m towers are independently determined.

Analysis of the upwelling irradiance measurements indicated that applying ratio tests comparing the upwelling broadband MFR irradiances to the appropriate collocated comparison measurements is an effective approach for screening out suspect upwelling broadband data. Because the vegetation under the 10-m and 25-m towers differed from one another, the ratio of the MFR10M_BB to MFR25M_BB measurements exhibited large variations over the course of the year. Therefore, the BEFlux1long and PSP measurements provided more appropriate data screening comparison values. Analysis of a four-year period (Figure 10) was used to establish limits of 0.75 to 1.75 for the ratio of the MFR upwelling irradiance measurements to the BEFlux_UP and the PSP25M upwelling irradiance values for the 10-m and 25-m towers, respectively. 


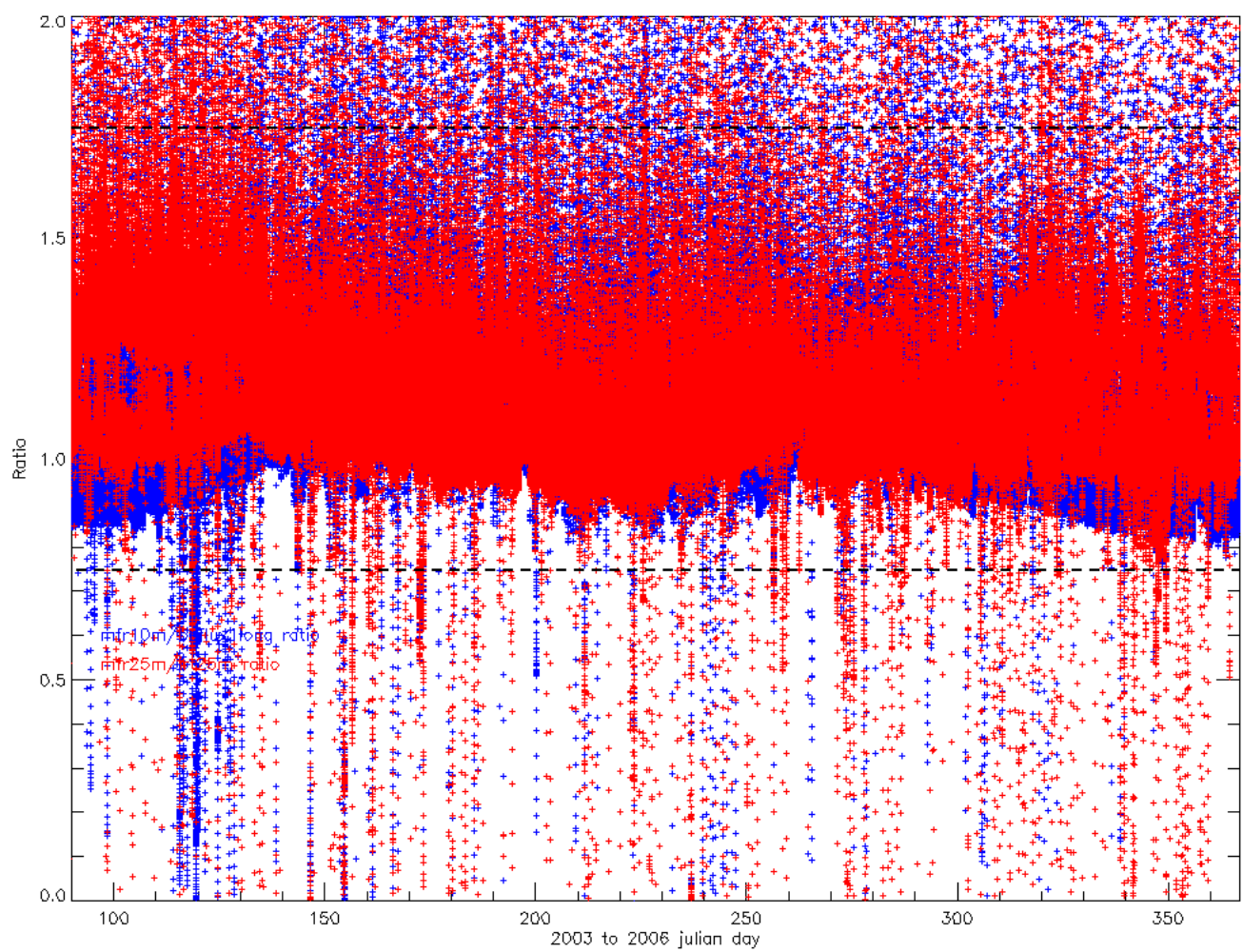

Figure 10. Ratios of upwelling irradiance values for 2003 to 2006.

The wider range of possible 'good' upwelling irradiances in the MFR narrowband measurements made the development of an appropriate limit to apply to ratio tests for the upwelling narrowband irradiances more difficult. An additional test to vet the upwelling narrowband irradiance (and one that was found to also be applicable to broadband upwelling irradiances) was developed using the running standard deviation of the percent difference of the individual MFR upwelling irradiance measurements to the average of all available upwelling irradiances. Available broadband upwelling data include the two MFRs at the 10-m and 25-m towers, the BEFlux1Long, and PSP. For upwelling narrowband, only the two MFRs are available.

Analysis of the running standard deviation of percent difference for the MFR 10-m and 25-m broadband and narrowband irradiances for the period from 2003 to 2006 revealed an exponential fall off with a long tail. Diurnal analysis of the standard deviation of percent difference over several seasons revealed the cutoff limit could be set at 0.03 and that many of the large standard deviation values occurred at low sun angles (sunrise, sunset). Therefore, removal of samples for which the cosine of the solar zenith angle is less than 0.15 is applied as part of preprocessing performed on the upwelling irradiance data. Broadband upwelling data that pass the cosine solar zenith limit are then subjected to the ratio tests, followed by removal of values for which the standard deviation of percent difference is greater than 0.03 . The upwelling narrowband data are subjected to only the cosine solar zenith and standard deviation tests.

In addition to these specialized tests, preprocessing includes the application of more stringent min and max limit tests applied to the MFR10M, MFR25M, and PSP25M irradiances. Specifically, the maximum upwelling broadband limit is decreased from 5000 to 1000 counts, and the MFR10M, MFR25M, and 
PSP25m broadband minimum are set to $0 \mathrm{~W} / \mathrm{m}^{\wedge} 2$. If a measurement limit (min, max, or delta) test is found to fail the irradiance value, it is deemed 'BAD' and replaced with a missing value.

The logic and QC flags for MFR10M_BB and MFR25M_BB are shown in Figure 11, and the logic and QC flags for MFR10M_NB and MFR25M_NB are shown in Figure 12.

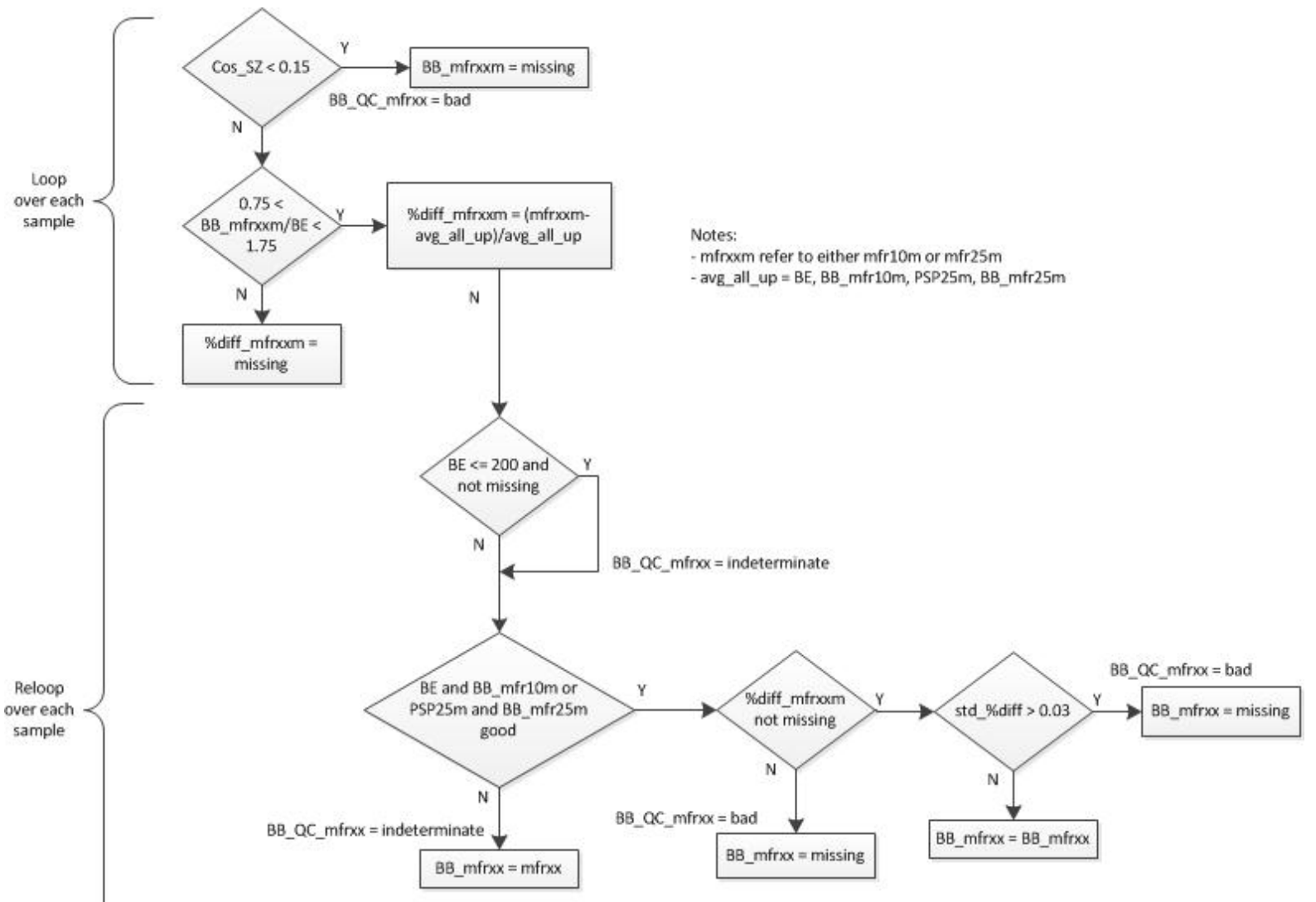

Figure 11. Logic for calculation of upwelling broadband best-estimate irradiance. 


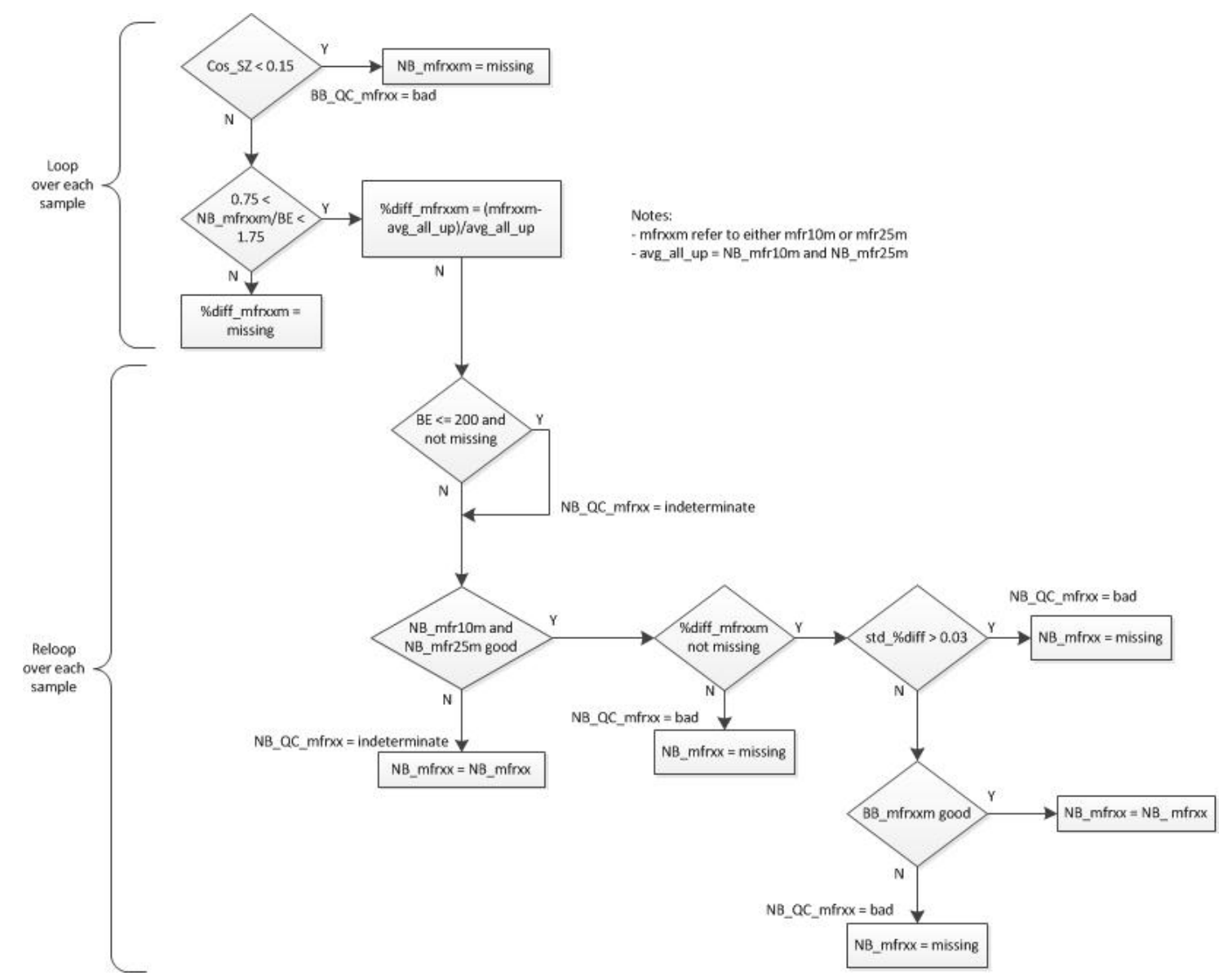

Figure 12. Logic for calculation of best-estimate upwelling narrowband irradiance.

For both the upwelling broadband and narrowband analysis, if fewer than 5 minutes of good data are found when attempting to define the end of a bad period during the process of estimating data (described in Section 5.2), the good samples are considered bad.

After the tests described above have been applied, missing and bad upwelling data samples are replaced using estimations based on the ratio of the value to its known good value where possible (as described in Section 5.3).

\subsection{Calculating Broadband and Narrowband Albedo}

Having found the best-estimate values for broadband and narrowband spectral upwelling and downwelling irradiances, the data deemed good are used to calculate albedo for the MFR10m and MFR25m locations.

Because of large uncertainties in calculating albedo during periods with small downwelling and upwelling broadband values, samples for which the downwelling broadband BEFlux1long irradiance is less than the greater of $50 \mathrm{Wm}^{-2}$ and the cosine of the solar zenith angle at solar noon multiplied by 100 are filtered out before calculating albedo. Narrowband albedo is calculated for all samples for which the narrowband data are considered good, and for which a broadband albedo could be calculated. 
Having calculated the albedo for all data assessed as 'good', missing albedos are estimated. The estimation of missing albedo is performed differently for 'direct' and 'diffuse' sky conditions. 'Direct' sky conditions refer to times when the downwelling solar flux is dominated by the direct beam, identified as periods when the BEFlux1longC1 direct shortwave measurement is greater than or equal to $15 \%$ of the BEFlux1longC1 downwelling total shortwave irradiance. 'Diffuse' sky conditions refer to times when the downwelling flux is dominated by the diffuse beam, and are identified as periods for which the ratio of BEFlux1long direct to total irradiance is less than $15 \%$.

Under diffuse conditions, there is little direct component, so the relationship of 'diffuse' albedo points versus the cosine of the solar zenith angle is relatively constant over time. However, for 'direct' conditions, there is a nearly linear relationship between albedo and the cosine of the solar zenith angle. Figure 13, an image of the relationship between the 'diffuse' and 'direct' albedos, illustrates how the two merge as the solar zenith angle approaches solar noon. How albedos are estimated for each of these conditions is described in the following sections.

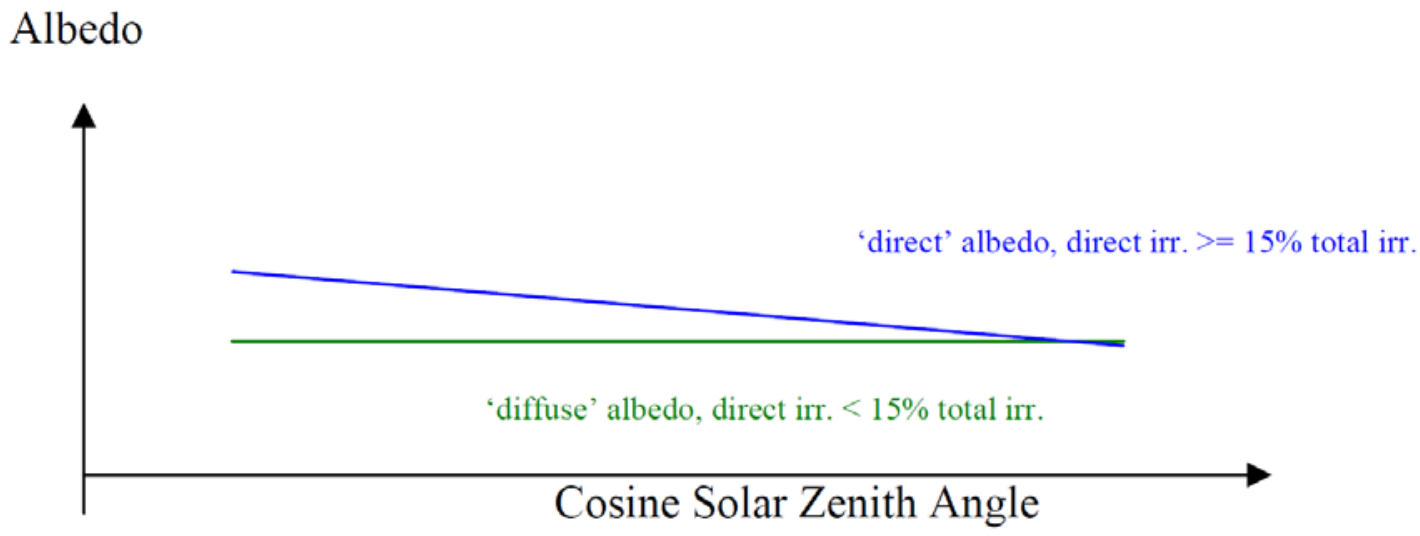

Figure 13. Cartoon illustrating the relationship of albedo to the cosine of the solar zenith angle for direct and diffuse conditions.

\subsubsection{Calculation of Albedo Noon}

During cloudy conditions where the primary irradiance is diffuse in nature (excluding periods of snow melt), the broadband and spectral albedo for a given day are relatively constant. As a result, the albedo of samples occurring during diffuse irradiance conditions can be easily estimated as an average of the albedo of the available diffuse points. Because the 'diffuse' albedo is approximately equal to the 'direct' albedo for a period of an hour before to after solar noon, this albedo is also referred to as the albedo noon value. The albedo noon value for a given day is determined as follows:

- If there are 50 or more 'good' diffuse points available for the period from one hour before to one hour after solar noon, calculate the albedo noon as the average of the good points.

- Else if there are at least 50 diffuse points available over the entire day, calculate the albedo noon as the average of the 50 good points.

- Else if there are 50 good albedo values (either diffuse or direct) available for the period from one hour before to one hour after solar noon, calculate the albedo noon value using all points in this period.

- If none of the conditions are met, then set albedo noon to missing value. 
If there are not enough points in a day to directly calculate an albedo noon value, then it is estimated by linearly interpolating between days for which the values could be determined.

Figure 14 presents results for an overcast day for which all points measured were found to be of type 'diffuse'. The top panel shows the measured global and direct downwelling irradiance and the upwelling irradiance, with a period of missing values near Julian Day 50.90. In the analysis of downwelling broadband presented in Section 5.1, it was discovered that for periods associated with a BEFlux1long downwelling broadband irradiance of less than $200 \mathrm{~W} / \mathrm{m} 2$, and for which neither the mfrsrC1 or mfrsrE13 downwelling broadband is within $10 \%$ of the BEFlux1longC1 downwelling broadband, it is not possible to accurately estimate broadband irradiance because the small irradiance values skew the irradiance ratio tests for these periods. Therefore the irradiances for this period could not be estimated. The middle panel shows that the measured broadband and spectral albedo are nearly constant with time across the day, as is usual in 'diffuse' conditions. For this case, there are sufficient 'diffuse' samples, shown in black in the bottom panel of Figure 14, around local noon to allow the calculation of an albedo noon value of 0.1429 for this day. Since all missing points in this day were 'diffuse', the estimated albedo values (purple stars) were set equal to the albedo noon value.
Albedo for SGP C1 25m, Feb 19, 2005
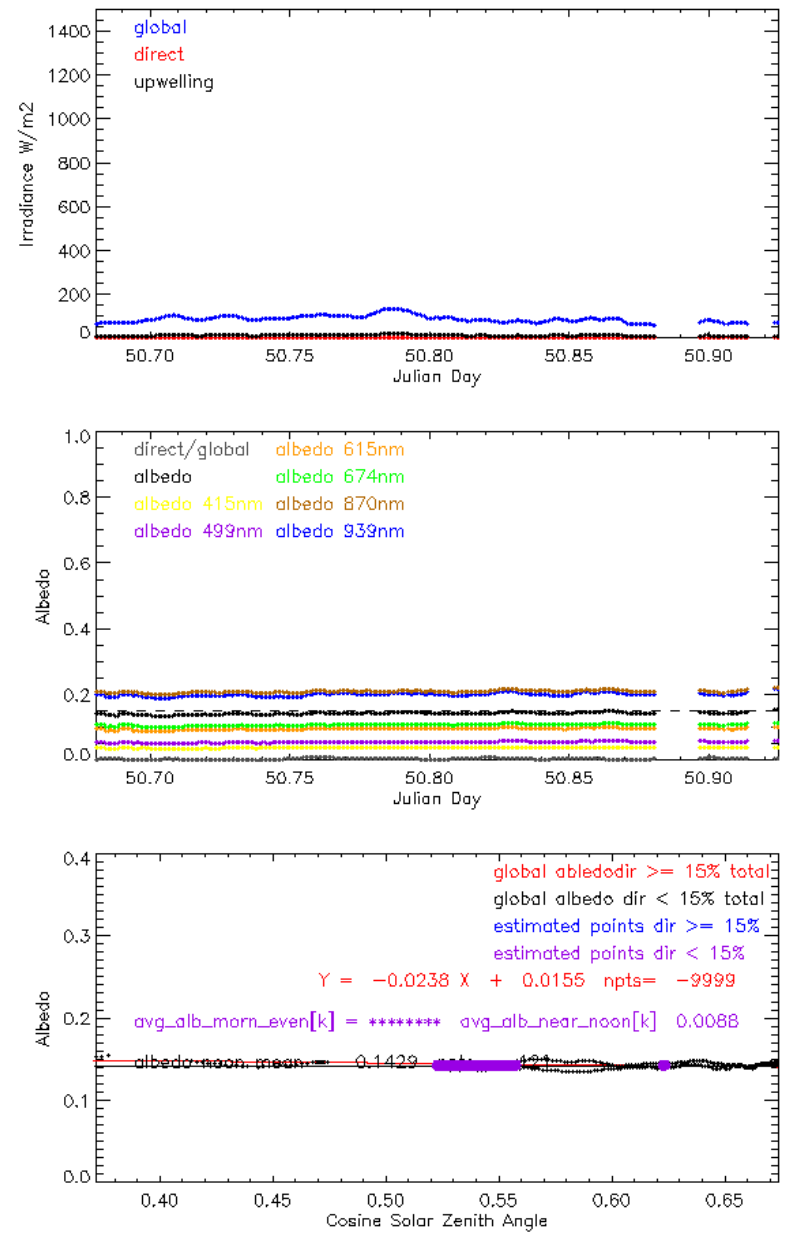

Figure 14. (top) Measured irradiance, (middle) measured albedo, and (bottom) estimated albedo for a typical overcast day.

\subsubsection{Calculation of 'Direct' Albedo Slope and Offset}

During a given day, the broadband and spectral albedo for 'direct' conditions can be estimated by calculating the slope of the available 'direct' albedo samples to the cosine of the solar zenith angle. To improve the accuracy of the 'direct' albedo estimations, the overcast albedo is separated from the 'direct' albedo prior to performing the linear fit by subtracting the value of the 'diffuse' albedo from the 'direct' albedo samples. This results in a fit to 'direct' samples with an offset equal to the overcast albedo value. To ensure the likelihood of a good fit, only samples with ratio of direct to total irradiance greater than $20 \%$ (rather than the 15\% used to define direct conditions) are included in the fit. To avoid poor fits that can occur from clumping of data around solar noon, a fit is not attempted if the minimum solar zenith angle for 'good' direct periods divided by the cosine of the solar zenith angle at solar noon is less than 0.9 . 
Finally, to avoid poor fits due to poor distribution of 'direct' albedo across any part of the day, the fit is anchored to the average albedo noon value. The anchoring is done by adding additional samples with direct minus diffuse albedo difference of zero to be used in the fit. The number of samples added is equal to five percent of the total number of good 'direct' samples.

When there are not enough good points in a day to directly calculate the albedo slope and offset, it is estimated by interpolating linearly between days for which the values could be determined. An example of this can be seen in the overcast day discussed in the previous section (Figure 14). Because all measurements for this day were found to be of type 'diffuse,' it was not possible to calculate the 'direct' slope and offset directly from information available for this day. This failure is noted in the bottom panel of Figure 15 as the number of direct samples used to calculate the direct albedo characteristics is given as ‘****'. The direct albedo slope and offset (values presented in red) of -0.0238 and 0.0155 were found through linear interpolation of these same values associated with days closest to Feb 19, 2005. The line produced by this slope and offset from the interpolated direct values is plotted in red in Figure 14 (bottom panel). Such an interpolation between days is also used when the number of available good direct albedo samples is too small to provide a basis for a good estimation of the direct albedo slope and offset.

An example of a day that is characterized by 'direct' conditions is shown in Figure 15. The grey line in the middle panel shows that the ratio of diffuse to total irradiance is above $15 \%$ for the whole day. This is also apparent from the lack of any points for the 'diffuse' case in the bottom panel, which plots the broadband albedo versus cosine of solar zenith angle. On this day there were a handful of points for which missing irradiance values could not be estimated and the albedo could not be directly calculated. These values are estimated using the 'direct' albedo offset and slope calculated for the day and are plotted in blue on the bottom panel. The estimated points lie relatively close to the measured (red points) 'direct' albedo values for this day. While no 'diffuse' points need to be estimated on this day, the albedo noon value is indicated on the bottom plot by the horizontal solid black line with a value of 0.2229.

A final example, Figure 16, illustrates the estimation process for a partly cloudy day where there are samples to be estimated for both the 'diffuse' and 'direct' conditions.

The dashed line in Figure 16 (middle panel) indicates the threshold of 15\% used on the ratio of direct/global to separate 'direct' and 'diffuse' conditions. Estimated 'diffuse' points are indicated by purple stars and estimated 'direct' points by blue stars in the bottom panel of Figure 16.

For the narrowband spectral channels, the direct and diffuse albedos are estimated in exactly the same way, but with separate fits calculated for each narrowband channel. For a partly cloudy day, the individual narrowband albedo noon, 'direct' albedo offset and slope, and resulting albedo estimations are presented in Figures 17 and 18.

Values for which albedo was estimated, rather than directly calculated, are flagged as such in the output file so that the user can restrict their analysis only to the use of directly calculated albedos, if desired.

The magnitude and slopes for the narrowband values differ slightly with the larger wavelengths having larger values and somewhat steeper slopes, but the albedo estimation approach appears to be as robust for the spectral channels as it is for the broadband. 
Albedo for SGP C1 25m, Mar 7, 2003
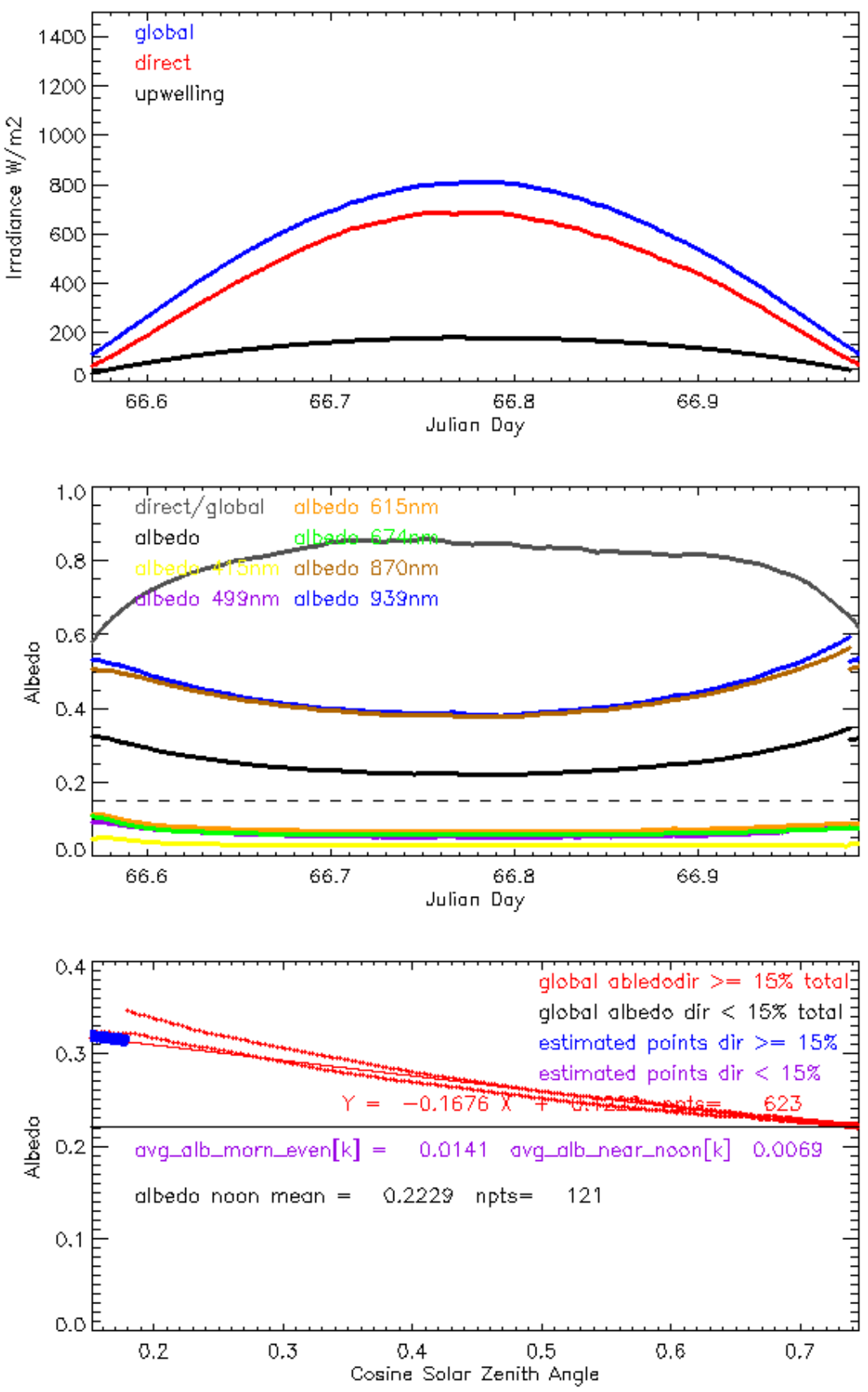

Figure 15. As in Figure 14, but for a typical clear sky day. 

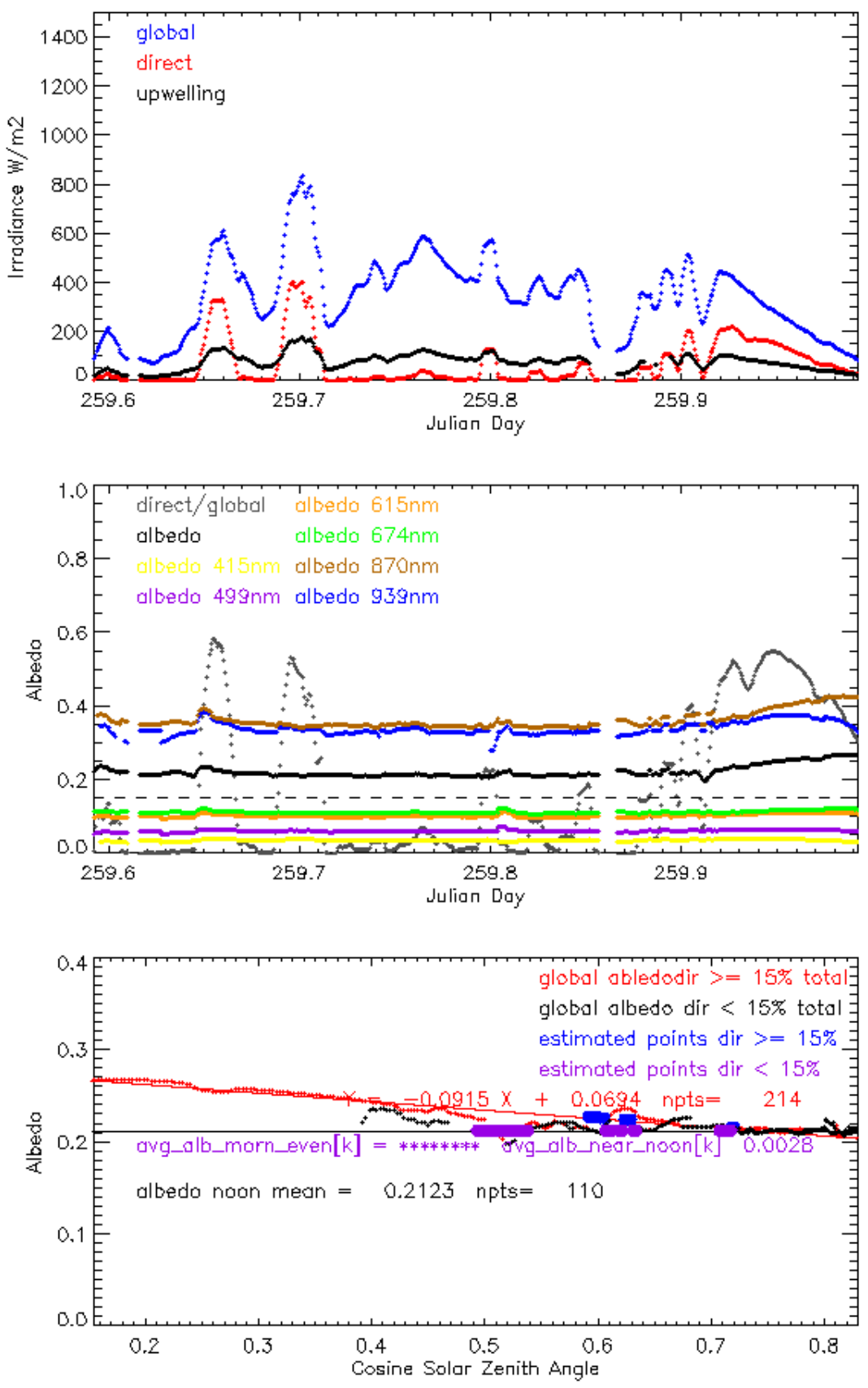

Figure 16. As in Figure 14, but for a partly cloudy day. 
Albedo for $415 \mathrm{~nm}, 499 \mathrm{~nm}$, and $615 \mathrm{~nm}$ data for sgp C1 10m, Sep 15, 2004
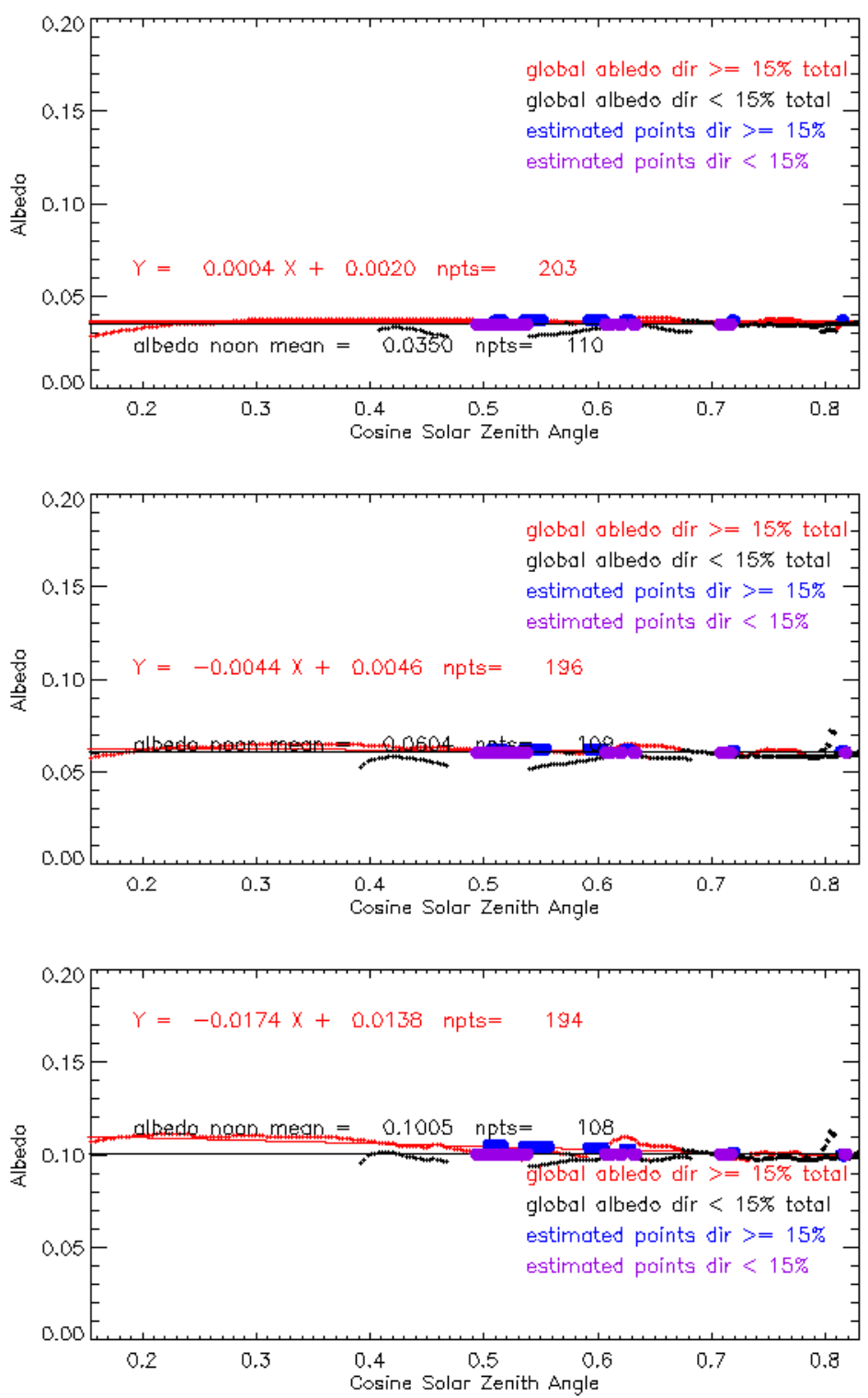

Figure 17. (top) Measured spectral irradiance, (middle) measured albedo, and (bottom) estimated albedo for a partly cloudy day at wavelengths $415 \mathrm{~nm}, 499 \mathrm{~nm}$, and $625 \mathrm{~nm}$. 

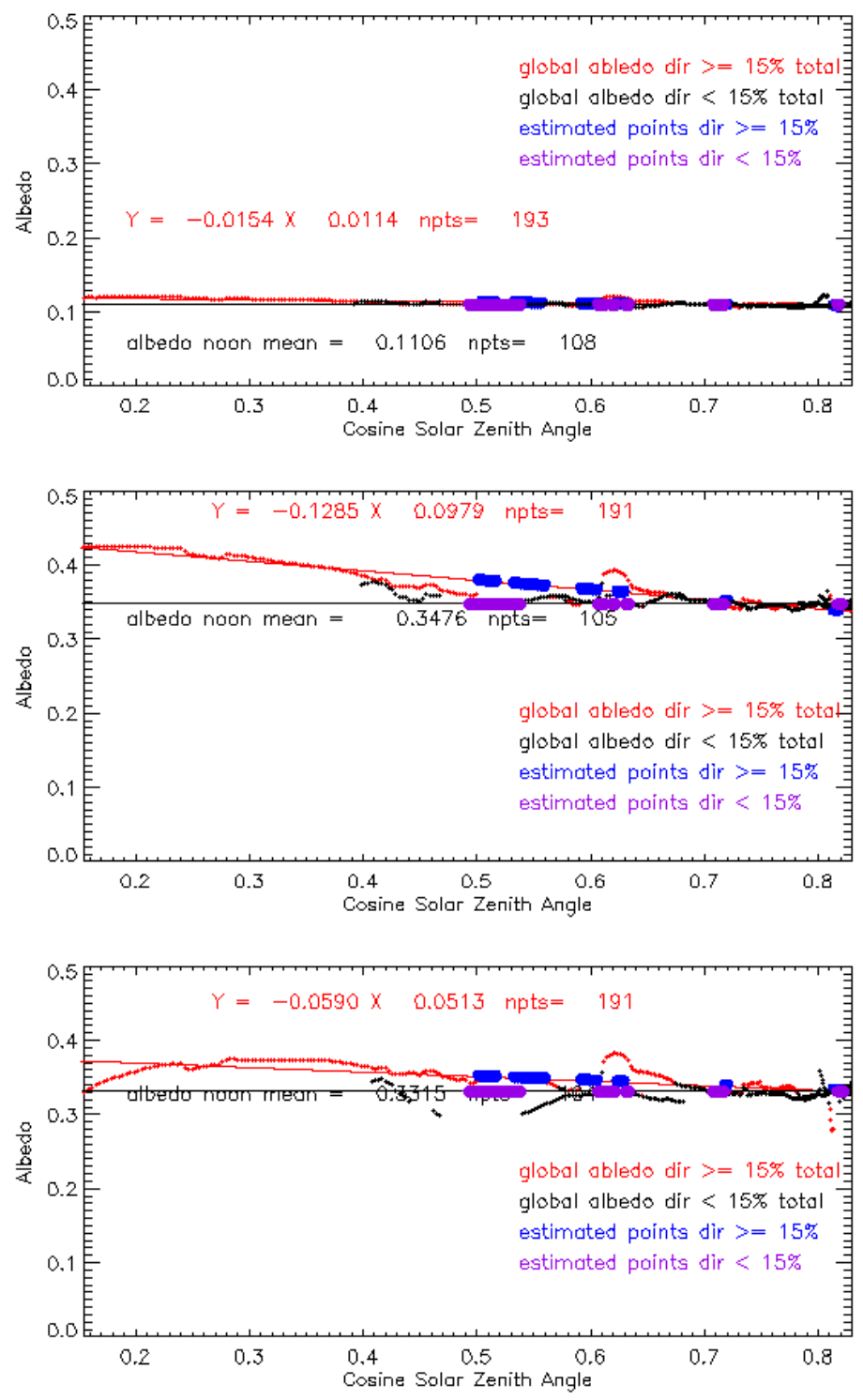

Figure 18. (top) Spectral irradiance, (middle) spectral measured albedo, and (bottom) spectral estimated albedo for a partly cloudy day at $674 \mathrm{~nm}, 870 \mathrm{~nm}$, and $939 \mathrm{~nm}$.

\subsubsection{Identifying Anomalous Albedo Conditions}

Anomalous albedo conditions refer to periods with sudden changes in the reflectance of the surface. Such sudden changes can occur either due to man-made effects such as the plowing of a field or natural events such as snowfall or snow melt. During these events, the surface albedo is not driven by the cosine of the solar zenith angle, thus the methodology for estimating albedo presented above is not effective during these periods. Therefore, best estimates are not determined during these periods of dramatic changes in albedo, and data affected by such a condition are flagged in the output data. 
Based on analysis of a six-year data period, these anomalous changes in albedo can be identified by setting limits on the expected variance in albedo across key periods in the day (defined in context of a range of solar zenith angles). In any day, a solar zenith angle occurs twice: once while the sun rises toward solar noon and again as it is setting. If the difference in average albedo before noon to that after noon is larger than a threshold value, then the occurrence of an anomalous albedo condition is assumed. An anomaly can also be identified even with gaps in the available data through the use of limits applied across two different solar zenith ranges: one near noon, and another near sunrise and sunset.

To keep the comparisons consistent throughout the year, the periods examined are defined as a fraction of the available solar zenith angles in each day. The possible solar zenith range for each day was defined as the minimum to maximum cosine solar zenith angle $\left(\mu_{0}\right)$ for which 'good' irradiance data existed. The 'morning/evening' solar zenith range was defined as values of $\mu_{0}$ falling from 20 to $35 \%$ of the available values of $\mu_{0}$ in the day. The 'near noon' test was defined as values of $\mu_{0}$ falling from 65 to $80 \%$ of the range in the day. An examination of the absolute differences in average surface albedos for these ranges over a six-year period found a limit of 0.05 was an appropriate limit for the variation between the morning and evening average albedo, and 0.03 for the near noon comparison.

The tests to identify anomalous albedo conditions are applied within the VAP as described below:

- If the difference in albedo between morning and evening is $<0.05$ and the difference in albedo near noon is $<0.03$, then there is no anomalous condition, and albedo estimations are performed as described previously.

- Else if cosine solar zenith $<$ median $\mu_{0}$ of available good data in day and the difference in albedo from morning to evening is $<0.05$, then there is no anomalous albedo and the albedo is estimated as appropriate.

- Else if cosine solar zenith $>=$ median $\mu_{0}$ of available good data in day and albedo difference near noon is $<0.03$, then there is no anomalous albedo condition and the albedo is estimated as appropriate.

- Else, anomalous albedo conditions are identified, the albedo values are set to -9999, and the data are flagged.

Figure 19 shows an example of an anomalous change in albedo across the course of a day, which is likely due to snow melt. In this case, the available values of $\mu_{0}$ over the day range from 0.15 to 0.53 . Therefore, the range for the morning to evening albedo test is $0.23<\mu_{0}<0.28$, and the range for the near-noon albedo test is $0.40<\mu_{0}<0.45$. The average albedo differences for the morning to evening and near-noon periods are 0.0601 and 0.0114 , respectively. The difference between morning and evening values is higher than the defined limit of 0.05 , correctly indicating an albedo anomaly occurred in either the morning or evening. In this particular case, no missing values needed to be estimated.

However, because the albedo difference near noon is not greater than 0.03 , the VAP would have allowed samples in the middle of the day with $\mu_{0}$ greater than the median $\mu_{0}$ value of 0.34 to be estimated had it been necessary, and would have prevented estimation for samples with $\mu_{0}$ less than 0.34 . This example illustrates how the use of two different periods for testing allows missing albedo values to be estimated over a portion of a day not affected by a temporally short anomalous albedo condition. 
Figure 20 illustrates a case where the anomalous albedo changes are minor and albedo estimations could be made with relatively good accuracy.

Albedo for SGP C1 10m, Jan 12, 2001
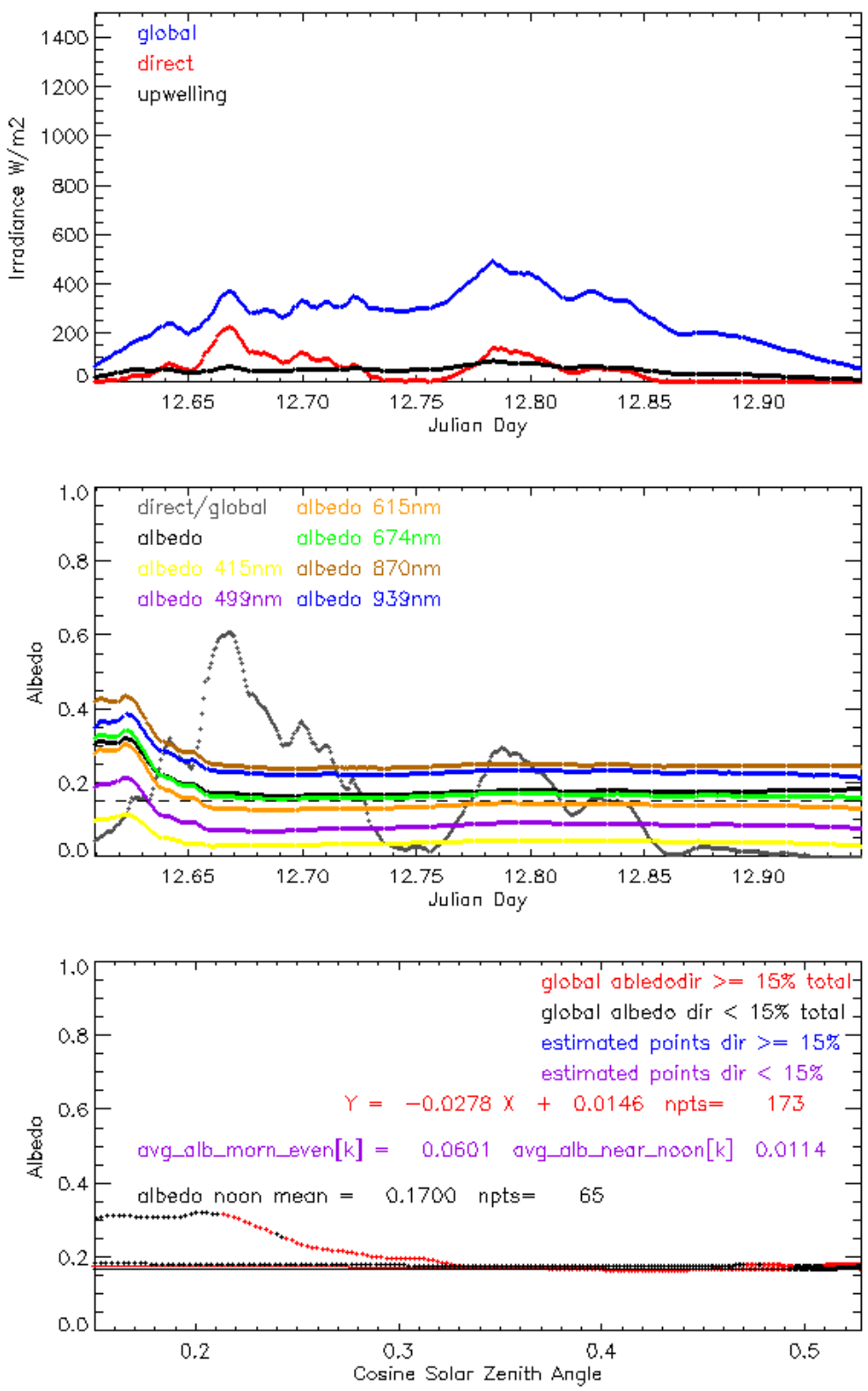

Figure 19. (top) Measured broadband irradiance, (middle) calculated spectral and broadband albedo, and (bottom) estimated broadband albedo. Figure shows a case (January 12, 2001) where large variations in albedo are seen at small cosine of solar zenith angle values. 

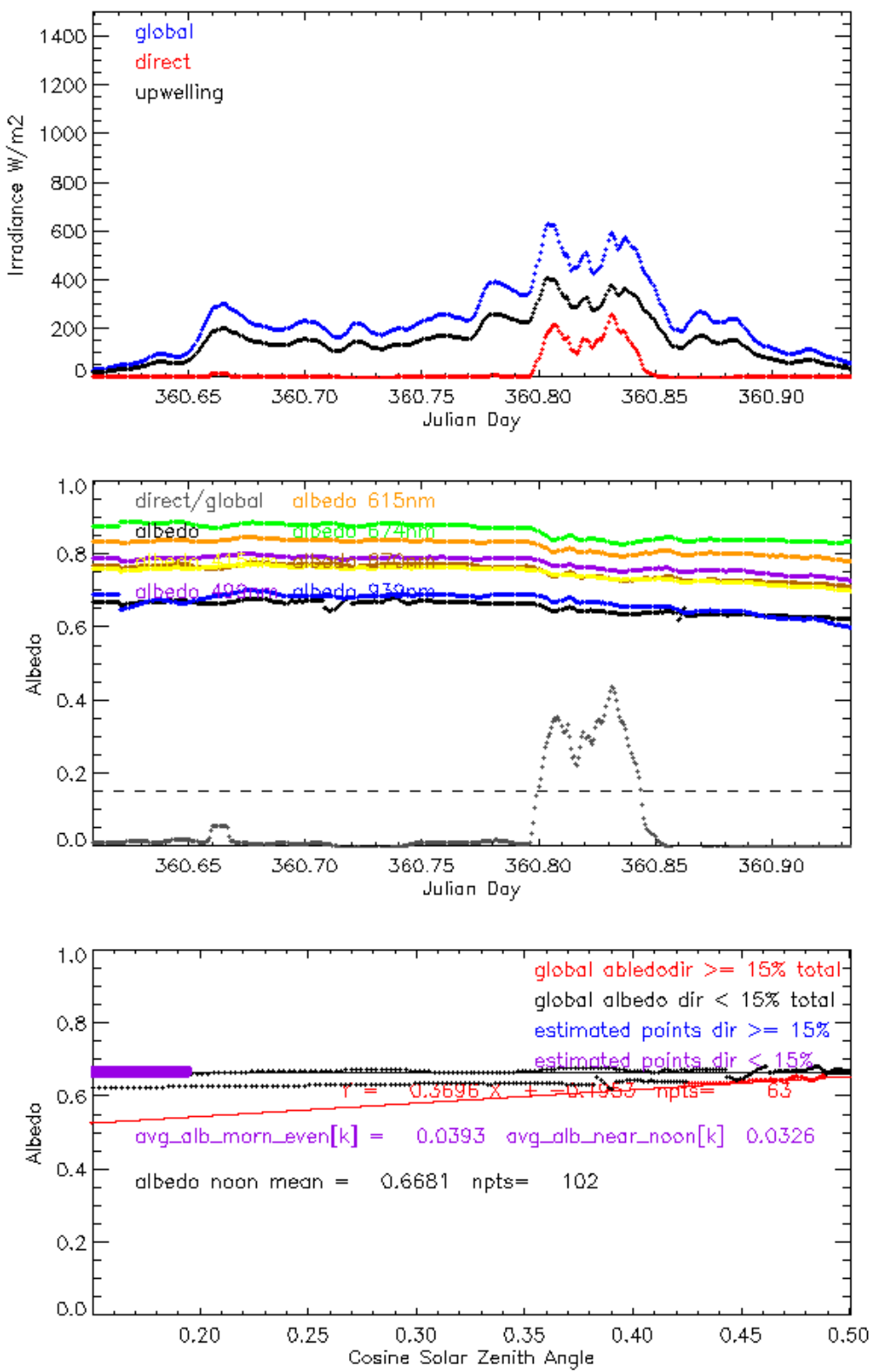

Figure 20. Example case where missing albedos are estimated (December 26, 2002 at SGP). 


\subsection{Estimation of High Resolution Spectral Albedo}

Once the best-estimate narrowband albedo values have been determined, we use them to estimate the high spectral resolution albedo at the sites. First, we use ratios of the narrowband albedos at several wavelengths to determine the surface type (vegetation, partial vegetation, brown, snow), then we extrapolate the narrowband measurements to high spectral resolution using piecewise continuous functions developed for each surface type from a set of spectral albedo libraries. Details of the algorithm development and testing of both the surface type estimation and the spectral extrapolation method are given in McFarlane et al. (2011); here we give only a brief overview of the algorithm and its implementation in the VAP.

\subsection{Identification of Surface Type}

The spectral albedo of a land surface is a function of the existence and type of vegetation that covers the area; we assume that if a set of surface types that characterize a site and result in unique spectral albedo signatures can be identified, they can also be used to predict the spectral albedo. Through examination of the MFR narrowband albedos, along with visual assessments of surface type made by site personnel (documented in the sgpsurflogC1.c1 datastream; hereafter referred to as surflog) and images from the total sky imager (TSI), we determined that the MFR operating wavelengths could distinguish between vegetated, partially vegetated, brown, and snow surfaces. To remove the influence of solar zenith angle, the average narrowband albedo for a period from one hour before to one hour after solar noon was used to derive the surface type for each day.

Snow-covered surfaces can be identified by their high visible albedo and the ratio of visible to near-IR albedos. Albedo thresholds for identifying snow (given in Table 3) were determined based on libraries of spectral albedo values (Bowker et al. 1985, ASTER 1999). Snow albedo varies significantly based on the age, thickness, and grain size of the snow and whether the underlying surface can be seen beneath the snow. Since we had few validation cases for snow, if the albedo test indicates a snow-covered surface, then a spectral extrapolation is not performed at this time. Analysis of field experiment data during conditions where scattered snow and ice existed on a surface indicate that the six MFR spectral measurements may not be able to identify snow as it starts melting and the underlying surface begins to show through the snow cover. Thus, in use of the MFR data operationally, the extrapolated albedos for several days after an identified snow case should be treated with caution.

If the surface is not snow-covered, we determine whether it is vegetated, partially vegetated, or nonvegetated by using a version of the Normalized Difference Vegetation Index (NDVI). The NDVI is an established indicator used by the remote sensing community to measure the amount of green vegetation in a surface (Myneni et al. 1995) and is based on the fact that green vegetation preferentially absorbs radiation at visible spectral wavelengths and reflects radiation at near-infrared wavelengths. It is calculated as the ratio of the difference between the near-infrared (NIR) and red reflectance to the sum of these same values.

$$
\mathrm{NDVI}=(\mathrm{NIR}-\mathrm{RED}) /(\mathrm{NIR}+\mathrm{RED})
$$


For the MFR instruments, we use the $870 \mathrm{~nm}$ (filter 5) measurement as the NIR value and the $673 \mathrm{~nm}$ (filter 4) measurement as the red value. NDVI is normalized to values between -1 and +1 . In general, dense vegetation has a high NDVI, bare soil has low positive values, and water has negative values due to strong NIR absorption (Myneni et al. 1995). Although NDVI is a useful tool for studying vegetation characteristics, the thresholds for determining whether a surface is vegetated or not depend on the details of the surface under consideration, the field of view of the instrument, and the wavelength channels used. To define thresholds for non-vegetated and $100 \%$ vegetated surfaces, we visually inspected the MFR albedo plots from several years and identified days that could be considered vegetated and non-vegetated. Based on the NDVI values in these cases, as well as examination of the differences between measured and estimated albedos, we obtained the threshold values given in Table 3. We also examined the use of other MFRSR channels, but found that the $673 \mathrm{~nm}$ and $870 \mathrm{~nm}$ channels gave the best separation.

Table 3. Albedo and NDVI thresholds for determining surface type.

\begin{tabular}{|c|c|}
\hline Surface Type & Surface Type Criteria \\
\hline Snow & $\alpha(415)>0.17 \& \& \alpha(615) / \alpha(870)>0.65$ \\
\hline $100 \%$ vegetation & NDVI $\geq 0.58$ \\
\hline Partial vegetation & $0.25<$ NDVI $<0.58$ \\
\hline $0 \%$ vegetation (brown) & NDVI $\leq 0.25$ \\
\hline
\end{tabular}

For partial vegetation cases, we assume that the albedo can be estimated as a weighted average between the estimated spectral albedos of fully vegetated and non-vegetated surfaces,

$$
\alpha_{p}=f \alpha_{100}+(1-f) \alpha_{0},
$$

where $f$ is the vegetation fraction and $\alpha_{\mathrm{p}}, \alpha_{100}$, and $\alpha_{0}$ are the albedos of the partially vegetated surface, fully vegetated surface, and non-vegetated surface, respectively. Based on several studies (Wittich and Hansing 1995, Kustas et al. 1993), we determine vegetation fraction as a function of the measured NDVI, and the NDVI values for the fully vegetated $\left(\mathrm{NDVI}_{100}\right)$ and non-vegetated surfaces $\left(\mathrm{NDVI}_{0}\right)$,

$$
f=\frac{\left(N D V I-N D V I_{0}\right)}{\left(N D V I_{100}-N D V I_{0}\right)}
$$

The time series of estimated surface type at SGP is shown in Figure 21. For the 25-m tower, the years 2001-2004 and 2005-2008 are plotted separately because of the different crops grown under the tower in those years. During the 2001-2004 period, the field below the MFR25M was routinely planted with winter wheat, but from 2005 onwards the crops have varied from year to year with wheat, soybeans, and corn all being planted at various times (Pat Dowell, personal communication, 2011). 

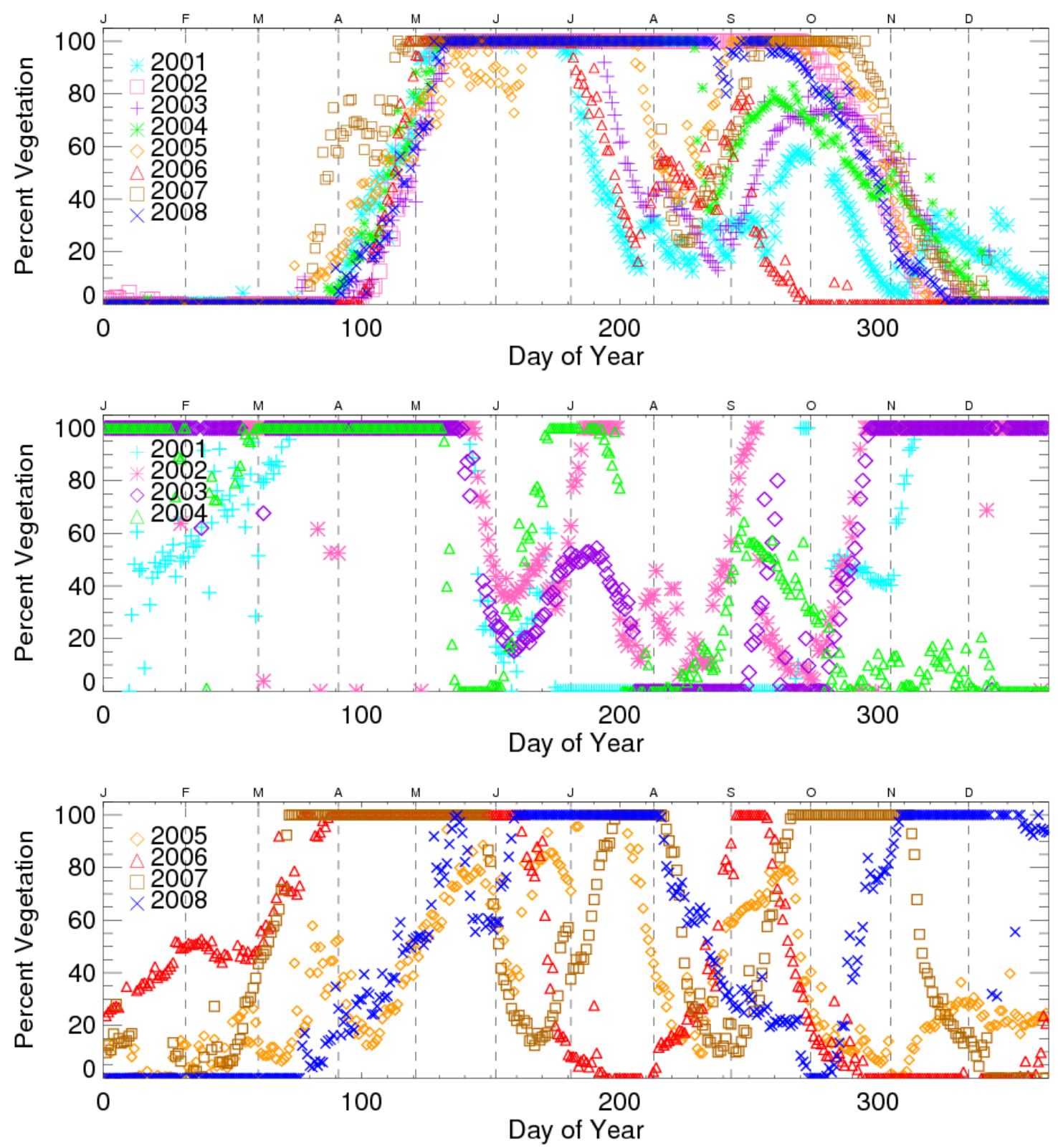

Figure 21. Time series of estimated surface type for (top) 10-m tower from 2001-2008, (middle) 25-m tower for 2001-2004, and (bottom) 25-m tower from 2005-2008.

At the 10-m tower, the initial spring growth of the grass in the un-mown pasture under the 10-m tower and the rapid increase from $0 \%$ to $100 \%$ vegetation can be clearly seen (top panel) and seems to occur near the same time each year. Each summer, the percent vegetation decreases from $100 \%$ to approximately $20 \%$ as the grass dies in the summer heat. Then percent vegetation increases again in the fall, before falling off to $0 \%$ in the winter. The timing and magnitude of the summer decrease and fall recovery vary from year to year, likely due to changes in precipitation. 
The annual cycle at the 25-m tower is more complicated because of the change in crops. From 2001 through the spring of 2004 (middle panel), the site shows 100\% vegetation in the winter months (November-May) due to the growth of winter wheat, which is typically planted in Sept/Oct and harvested in June (USDA 1997). A minimum in percent vegetation occurs around June in most years, although some years show an increase in vegetation again immediately after the presumed harvest. This may be due to weeds growing in the fallow fields (as seen in images in the field reports) and periodic plowing of the fields. A gradual greening up of the 25-m tower site begins again in fall, when the winter wheat is planted (although this did not happen in the fall of 2004 due to the change in crops). The annual cycle at the 25-m tower changes during the 2005-2008 period (bottom panel) due to the change in farming practices. During this period, the crops planted (wheat, corn, soybeans) vary from year to year, and each has a different planting and harvesting time, so the annual cycle of surface type is quite variable.

\subsection{Estimation of High Resolution Spectral Albedo}

Once the surface type and percent vegetation for each day are determined, we use the narrowband bestestimate albedo measurements and a spectral extrapolation method to derive the high spectral resolution albedo at $60 \mathrm{~s}$ temporal and $10 \mathrm{~cm}^{-1}$ spectral resolution.

Several libraries of high spectral resolution albedo measurements of various surface types were used to develop the spectral extrapolation method (Bowker 1985, ASTER 1999). Peaks and troughs in the spectral albedo functions were used to identify distinct spectral regions. Piecewise continuous functions were calculated for vegetated and non-vegetated surfaces to estimate the albedo across each spectral region given the input albedos at the MFR wavelengths. The surface type and percent vegetation estimate is made once per day, using an average of the MFR data for an hour before/after solar noon. For each MFR sample time, the six narrowband albedos are used to scale the function for the appropriate surface type. The functions produce albedo from 820 to $50,000 \mathrm{~cm}^{-1}$ at $10 \mathrm{~cm}^{-1}$ resolution. For partially vegetated surfaces, the spectral albedos for vegetated and non-vegetated surfaces are calculated separately and then weighted by the percent vegetation.

Examples of the extrapolated high resolution spectral albedo for several days are shown in Figure 22. Also shown are high spectral resolution albedos from spectral measurements taken during several Intensive Observing Periods (IOPs) at the SGP site (Trishchenko et al. 2003, 2004a, 2004b). More extensive evaluations of the extrapolated albedos using the IOP measurements are shown in McFarlane et al. (2011). 

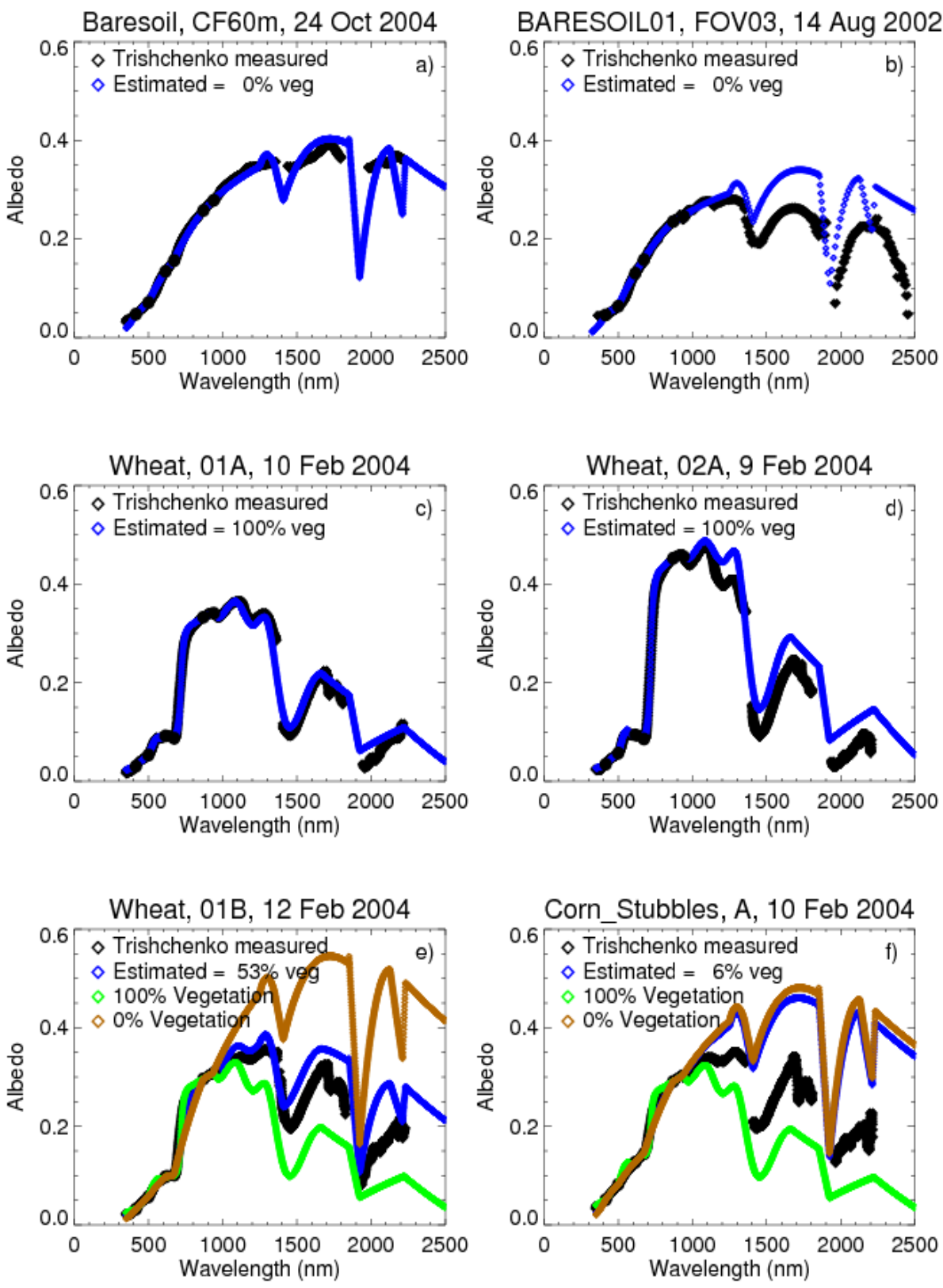

Figure 22. Examples of spectrally resolved albedo values from IOP measurements (black diamonds), estimation methodology using estimated percent vegetation (blue), estimation methodology assuming $100 \%$ vegetation (green), and estimation methodology assuming $0 \%$ vegetation (brown). For cases where the estimated surface type was $0 \%$ or $100 \%$ vegetation, only those estimated values are shown. Cases represent (a, b) non-vegetated surfaces, (c, d) fully vegetated surfaces, and $(e, f)$ partially vegetated surfaces. 


\subsection{Comparison to Broadband Albedo Measurements}

As an additional evaluation of the spectral extrapolation methodology, we compare the broadband albedo calculated by integrating the extrapolated high spectral resolution albedos $\left(\alpha_{\text {int }}\right)$ to the broadband albedos measured by the PSP radiometers on the $10-\mathrm{m}$ and $25-\mathrm{m}$ towers $\left(\alpha_{\mathrm{PSP}}\right)$. To integrate the spectral albedo up to a broadband value, we weight the albedos by the spectrum of downwelling irradiance at the surface:

$$
\alpha_{B B}=\int \alpha_{\lambda} S_{\lambda} d \lambda / \int S_{\lambda} d \lambda
$$

where $\alpha_{\lambda}$ is the simulated high spectral resolution albedo and $S_{\lambda}$ is the spectrum of downwelling solar irradiance at the surface. For this analysis, we use a single solar spectrum at the surface calculated from the CHARTS high resolution spectral radiative transfer model (Clough et al. 2005) for a clear-sky case at the SGP site to weight the spectral albedo values in the integration. Although the water vapor loading at the SGP site (and hence the solar flux at the surface) varies over the course of the year, the spectral distribution of the water vapor absorption does not change, giving some universality to the shape of the spectrum used in the weighting.

We examine the difference between the integrated albedo and measured broadband albedo from the PSPs at each tower for near-noon values for each day between 2003-2008 for which a valid surface type and valid PSP measurements exist (Figure 23). In general, the agreement between the integrated and measured broadband albedo values is good, with standard deviation less than 0.015 for both towers and little dependence on vegetation type. For the 10-m MFR, the integrated values slightly overestimate the PSP broadband albedo, while the opposite is true of the 25-m MFR. Several outlier points are obvious in both the $10-\mathrm{m}$ and 25 -m cases. We first examined whether the outliers were caused by cases where the MFR albedos had to be estimated due to missing data (orange and purple points in Figure 24). These estimated points do have larger standard deviation than the non-estimated points, but similar means, and do not explain all of the large outliers. Further analysis of the individual points with residuals greater than 0.1 indicated that they were all due to problems with the input data sets that were not caught in the initial quality control checks.

The above analysis indicated that the comparison of integrated to measured broadband albedo could be useful as a quality control check to identify problems with the input data sets. In the final albedo data set, the integrated broadband albedo is included in the output file, and times with broadband residuals greater than 0.05 but less than 0.1 are flagged as indeterminate. Times with broadband residuals equal to or greater than 0.1 are flagged as bad, and the albedo values are replaced with -9999 . 

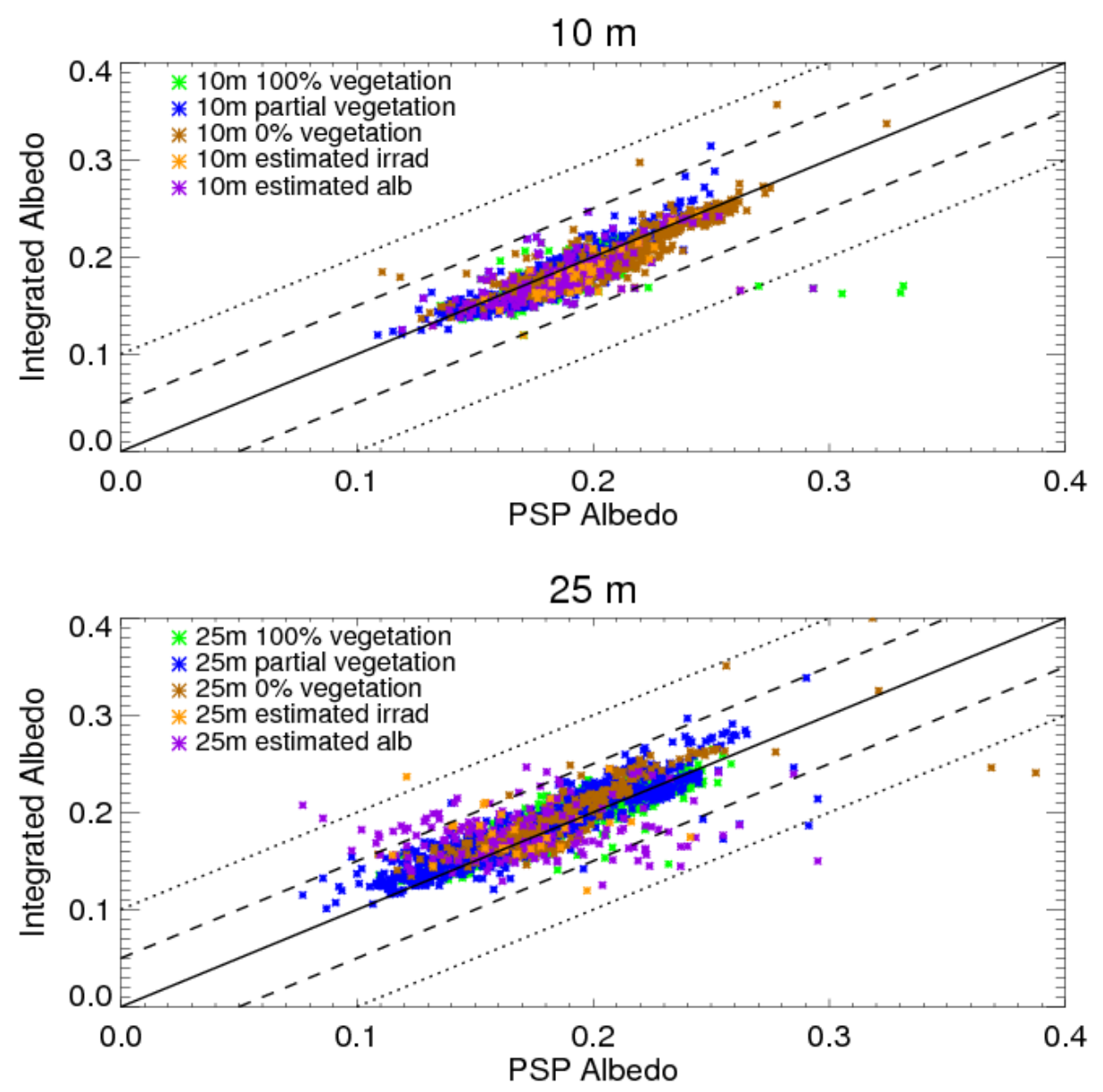

Figure 23. Plot of (top) 10-m and (bottom) 25-m integrated spectral albedos compared to measured broadband albedo values.

\subsection{Summary and Follow-On Efforts}

A methodology for filtering MFR and MFRSR irradiances, estimating missing and bad values, and subsequently calculating and best estimating broadband and narrowband surface albedo using the irradiances has been developed. The narrowband albedos are then used to estimate surface type and extrapolate to high spectral resolution albedos. These high resolution spectral albedo values will be used as input to the ARM Broadband Heating Rate Profiles (BBHRP) and Shortwave Quality Measurement Experiment (SW QME) projects, which compare calculated and measured radiative fluxes to assess our understanding of the various aspects involved in calculating radiative fluxes. In the current work, the effect of large-scale spatial heterogeneity on the estimated albedo was not considered, and no correction for cloud cover was implemented. To accurately calculate radiative fluxes, both of these factors should be included in the surface albedo used in the calculations. As part of the radiative transfer modeling associated with the BBHRP and SW QME projects, the impact of neglecting these factors will be investigated. 


\subsection{References}

ASTER Spectral Library courtesy of the Jet Propulsion Laboratory, California Institute of Technology, Pasadena, California. Copyright 1999, California Institute of Technology (http://speclib.jpl.nasa.gov/).

Bowker, DE, RE Davis, DL Myrick, K Stacy, and WT Jones. 1985. Spectral Reflectances of Natural Targets for use in Remote Sensing Studies. NASA Reference Publication 1139.

Clough, SA, MW Shephard, EJ Mlawer, JS Delamere, MJ Iacono, K Cady-Pereira, S Boukabara, and PD Brown. 2005. "Atmospheric radiative transfer modeling: A summary of the AER codes.” Journal of Quantitative Spectroscopy and Radiative Transfer 91: 233-244, doi:10.1016/j.jqsrt. 2004.05.058.

Kiedron, P, J Schlemmer, and M Klassen. 2006. Rotating Shadowband Spectrometer (RSS) Handbook. U.S. Department of Energy. DOE/SC-ARM/TR-051. http://www.arm.gov/publications/handbooks/rss_handbook.pdf

Kustas, WP, TJ Schmugge, KS Jumes, TH Jackson, R Parry, and MA Weltz. 1993. "Relationships between evaporative fraction and remotely sensed vegetation index and microwave brightness temperature for semiarid rangelands.” Journal of Applied Meteorology 32: 1781-1790.

McFarlane, SA, K Gaustad, CN Long, EJ Mlawer, and J Delamere. 2011. Development of a high spectral resolution surface albedo product for the ARM Southern Great Plains Central Facility. In preparation.

Myneni, RB, FG Hall, PJ Sellers, and AL Marshak. 1995. "The interpretation of spectral vegetation indexes.” IEEE Transactions on Geoscience and Remote Sensing 33(2): 481-486.

Pilewskie, P, and J Pommier. 2007. Shortwave Spectrometer (SWS) Handbook. U.S. Department of Energy. DOE/SC-ARM/TR-062. http://www.arm.gov/publications/handbooks/sws_handbook.pdf.

Shi, Y, and CN Long. 2002. Best Estimate Radiation Flux Value-Added Procedure: Algorithm Operational Details and Explanations. U.S. Department of Energy. DOE/SC-ARM/TR-008.

Trishchenko, AP, Y Luo, M Cribb, Z Li, and K Hamm. 2003. “Surface spectral albedo intensive operational period at the ARM SGP site in August 2002: Results, analysis, and future plans.” In Proceedings of the Thirteenth Atmospheric Radiation Measurement (ARM) Program Science Team Meeting. U.S. Department of Energy. Richland, Washington.

Trishchenko, AP, Y Luo, K Khlopenkov, and MJ Jeong. 2004a. Field Report 3rd Surface Albedo IOP Southern Great Plains (SGP) Cart Site February 8-12, 2004. Available from ARM IOP archive.

Trishchenko, AP, Y Luo, K Khlopenkov, and M Cribb. 2004b. Field Report $4^{\text {th }}$ Surface Albedo IOP Southern Great Plains (SGP) Cart Site October 20-26, 2004. Available from ARM IOP archive.

USDA. 1997. Usual planting and harvesting dates for U.S. field crops. United States Department of Agriculture. Agricultural Handbook No. 628.

Wittich, K-P, and O Hansing. 1995. "Area-averaged vegetative cover fraction estimated from satellite data.” International Journal of Biometeorology 38: 209-215. 


\section{Appendix A}

Table A.1. Input datastreams and variables required to run the SURFSPECALB VAP.

\begin{tabular}{|c|c|c|c|}
\hline Datastream & Variable Name & Variable Long Name & Units \\
\hline \multirow{3}{*}{$\begin{array}{l}X X X \text { beflux1longFF. } \\
c 1 \\
X X X \text { is sgp } \\
\text { FF is } C 1\end{array}$} & down_short_hemisp & $\begin{array}{l}\text { Downwelling Shortwave } \\
\text { Hemispheric Irradiance }\end{array}$ & $\mathrm{W} / \mathrm{m} 2$ \\
\hline & up_short_hemisp & $\begin{array}{l}\text { Upwelling (10 meter) Shortwave } \\
\text { Hemispheric Irradiance }\end{array}$ & $\mathrm{W} / \mathrm{m} 2$ \\
\hline & short_direct_normal & Shortwave Direct Normal Irradiance & $\mathrm{W} / \mathrm{m} 2$ \\
\hline \multirow{2}{*}{$\begin{array}{l}X X X \text { irt } 25 m F F . b 1 \\
X X X \text { is sgp } \\
\text { FF is C1 }\end{array}$} & up_short_hemisp & $\begin{array}{l}\text { Upwelling Shortwave Hemispheric } \\
\text { Irradiance, Pyranometer }\end{array}$ & $\mathrm{W} / \mathrm{m} 2$ \\
\hline & qc_up_short_hemisp & $\begin{array}{l}\text { Quality check results on field: } \\
\text { Upwelling Shortwave Hemispheric } \\
\text { Irradiance, Pyranometer }\end{array}$ & unitless \\
\hline \multirow{6}{*}{$\begin{array}{l}X X X m f r H H m F F . b 1 \\
X X X \text { is sgp } \\
\text { HH is } 10 \text { or } 25 \\
\text { FF is C1 }\end{array}$} & up_hemisp_boadband & $\begin{array}{l}<\mathrm{HH}>\text { meter Broadband Upwelling } \\
\text { Hemispheric Irradiance }\end{array}$ & counts \\
\hline & qc_up_hemisp_broadband & $\begin{array}{l}\text { Quality check results on field: }<\mathrm{HH}> \\
\text { meter Broadband Upwelling } \\
\text { Hemispheric Irradiance }\end{array}$ & unitless \\
\hline & $\begin{array}{l}\text { up_hemisp_narrowband_filter }< \\
x>\text { where } x=1 \text { to } 6\end{array}$ & $\begin{array}{l}<\mathrm{HH}>\text { meter Narrowband Upwelling } \\
\text { Hemispheric Irradiance, Filter }<\mathrm{N}>\end{array}$ & $\mathrm{W} /(\mathrm{m} 2 \mathrm{~nm})$ \\
\hline & $\begin{array}{l}\text { qc_up_hemisp_narrowband_filt } \\
\text { er }<N>\text { where } N=1 \text { to } 6\end{array}$ & $\begin{array}{l}\text { Quality check results on field: }<\mathrm{HH}> \\
\text { meter Narrowband Upwelling } \\
\text { Hemispheric Irradiance, Filter }<\mathrm{N}>\end{array}$ & unitless \\
\hline & cosine_solar_zenith_angle & Cosine Solar Zenith Angle & unitless \\
\hline & qc_cosine_solar_zenith_angle & $\begin{array}{l}\text { Quality check results on field: } \\
\text { Cosine Solar Zenith Angle }\end{array}$ & unitless \\
\hline \multirow{7}{*}{$\begin{array}{l}X X X m f r s r F F . b 1 \\
X X X \text { is sgp } \\
F F \text { is } C 1 \text { or E13 }\end{array}$} & hemisp_broadband & Hemispheric Broadband Irradiance & counts \\
\hline & qc_hemisp_broadband & $\begin{array}{l}\text { Quality check results on field: } \\
\text { Hemispheric Broadband Irradiance }\end{array}$ & unitless \\
\hline & $\begin{array}{l}\text { hemisp_narrowband_filter }<N> \\
\text { where } \mathrm{N} \text { is } 1 \text { to } 6\end{array}$ & $\begin{array}{l}\text { Narrowband Hemispheric } \\
\text { Irradiance, Filter }\langle\mathrm{N}\rangle\end{array}$ & $\mathrm{W} /(\mathrm{m} 2 \mathrm{~nm})$ \\
\hline & $\begin{array}{l}\text { qc_hemisp_narrowband_ } \\
\text { filter }<N>\text { where } N \text { is } 1 \text { to } 6\end{array}$ & $\begin{array}{l}\text { Quality check results on field: } \\
\text { Narrowband Hemispheric } \\
\text { Irradiance, Filter }<\mathrm{N}>\end{array}$ & unitless \\
\hline & diffuse_hemisp_broadband & $\begin{array}{l}\text { Diffuse Hemispheric Broadband } \\
\text { Irradiance }\end{array}$ & counts \\
\hline & qc_diffuse_hemisp_broadband & $\begin{array}{l}\text { Quality check results on field: } \\
\text { Diffuse Hemispheric Broadband } \\
\text { Irradiance }\end{array}$ & unitless \\
\hline & $\begin{array}{l}\text { diffuse_hemisp_narrowband_filt } \\
\text { er }<N> \\
\text { where } N \text { is } 1 \text { to } 6\end{array}$ & $\begin{array}{l}\text { Narrowband Diffuse Hemispheric } \\
\text { Irradiance, Filter }<N>\end{array}$ & $\mathrm{W} /\left(\mathrm{m}^{2} \mathrm{~nm}\right)$ \\
\hline
\end{tabular}




\begin{tabular}{|c|c|c|c|}
\hline Datastream & Variable Name & Variable Long Name & Units \\
\hline & $\begin{array}{l}\text { qc_diffuse_hemisp_narrowband } \\
\text { filter }<N> \\
\text { where } N \text { is } 1 \text { to } 6\end{array}$ & $\begin{array}{l}\text { Quality check results on field: } \\
\text { Narrowband Diffuse Hemispheric } \\
\text { Irradiance, Filter }<\mathrm{N}>\end{array}$ & unitless \\
\hline & direct_normal_broadband & Direct Normal Broadband Irradiance & counts \\
\hline & qc_direct_normal_broadband & $\begin{array}{l}\text { Quality check results on field: Direct } \\
\text { Normal Broadband Irradiance }\end{array}$ & unitless \\
\hline & $\begin{array}{l}\text { direct_normal_narrowband_filte } \\
\mathrm{r}<\mathrm{N}> \\
\text { where } \mathrm{N} \text { is } 1 \text { to } 6\end{array}$ & $\begin{array}{l}\text { Narrowband Direct Normal } \\
\text { Irradiance, Filter }<\mathrm{N}>\end{array}$ & $\mathrm{W} /\left(\mathrm{m}^{2} \mathrm{~nm}\right)$ \\
\hline & $\begin{array}{l}\text { qc_direct_normal_narrowband_ } \\
\text { filter }<N> \\
\text { where } N \text { is } 1 \text { to } 6\end{array}$ & $\begin{array}{l}\text { Quality check results on field: } \\
\text { Narrowband Direct Normal } \\
\text { Irradiance, Filter }<\mathrm{N}>\end{array}$ & unitless \\
\hline
\end{tabular}




\section{Appendix B}

\section{Output Data}

Table B.1: Variables in .c1 level output file from SURFSPECALB VAP. Variables noted in the fourth column (.s1) are the variables included in the summary .s1 level output files. In the table below, TT $=$ " $10 \mathrm{~m}$ " or “ $25 \mathrm{~m}$ ". At SGP, both $10-\mathrm{m}$ and $25-\mathrm{m}$ variables exist.

\begin{tabular}{|c|c|c|c|}
\hline Fieldname & Description & Units &.$s 1$ \\
\hline base_time & Base Time in Epoch & $\begin{array}{l}\text { seconds } \\
\text { since } \\
\text { 1970/01/01 } \\
\text { 00:00:00 }\end{array}$ & $x$ \\
\hline time_offset & Time offset from base_time & $\begin{array}{l}\text { seconds } \\
\text { since } \\
\text { base_time }\end{array}$ & $x$ \\
\hline time & Time offset from midnight & $\begin{array}{l}\text { seconds } \\
\text { since } \\
\text { midnight }\end{array}$ & $x$ \\
\hline filter & $\begin{array}{l}\text { Wavelength of each of the } 6 \text { Filters } \\
\text { Measured by the MFR Radiometers }\end{array}$ & $\mathrm{cm}$ & $x$ \\
\hline wavenumber & Wavenumber for a given sample time & $\mathrm{cm}^{-1}$ & $x$ \\
\hline hemisp_broadband_mfrsrC1 & Hemispheric Broadband Irradiance & counts & \\
\hline qc_hemisp_broadband_mfrsrC1 & $\begin{array}{l}\text { Quality check results on field: } \\
\text { Narrowband Hemispheric Irradiance }\end{array}$ & unitless & \\
\hline hemisp_narrowband_mfrsrC1 & Narrowband Hemispheric Irradiance & $\mathrm{W} /\left(\mathrm{m}^{2} \mathrm{~nm}\right)$ & \\
\hline qc_hemisp_narrowband_mfrsrC1 & $\begin{array}{l}\text { Quality check results on field: } \\
\text { Narrowband Hemispheric Irradiance }\end{array}$ & unitless & \\
\hline diffuse_hemisp_broadband_mfrsrC1 & $\begin{array}{l}\text { Diffuse Hemispheric Broadband } \\
\text { Irradiance }\end{array}$ & counts & \\
\hline $\begin{array}{l}\text { qc_diffuse_hemisp_broadband_mfrsrC } \\
1\end{array}$ & $\begin{array}{l}\text { Quality check results on field: Diffuse } \\
\text { Hemispheric Broadband Irradiance }\end{array}$ & & \\
\hline diffuse_hemisp_narrowband_mfrsrC1 & $\begin{array}{l}\text { Narrowband Diffuse Hemispheric } \\
\text { Irradiance }\end{array}$ & $\mathrm{W} /\left(\mathrm{m}^{2} \mathrm{~nm}\right)$ & \\
\hline $\begin{array}{l}\text { qc_diffuse_hemisp_narrowband_mfrsr } \\
\text { C1 }\end{array}$ & $\begin{array}{l}\text { Quality check results on field: } \\
\text { Narrowband Diffuse Hemispheric } \\
\text { Irradiance }\end{array}$ & & \\
\hline direct_normal_broadband_mfrsrC1 & Direct Normal Broadband Irradiance & counts & \\
\hline qc_direct_normal_broadband_mfrsrC1 & $\begin{array}{l}\text { Quality check results on field: Direct } \\
\text { Normal Broadband Irradiance }\end{array}$ & & \\
\hline direct_normal_narrowband_mfrsrC1 & Narrowband Direct Normal Irradiance & $\mathrm{W} /\left(\mathrm{m}^{2} \mathrm{~nm}\right)$ & \\
\hline
\end{tabular}




\begin{tabular}{|c|c|c|c|}
\hline Fieldname & Description & Units &.$s 1$ \\
\hline $\begin{array}{l}\text { qc_direct_normal_narrowband_mfrsrC } \\
1\end{array}$ & $\begin{array}{l}\text { Quality check results on field: } \\
\text { Narrowband Direct Normal Irradiance }\end{array}$ & & \\
\hline hemisp_broadband_mfrsrE13 & Hemispheric Broadband Irradiance & counts & \\
\hline qc_hemisp_broadband_mfrsrE13 & $\begin{array}{l}\text { Quality check results on field: } \\
\text { Hemispheric Broadband Irradiance }\end{array}$ & & \\
\hline hemisp_narrowband_mfrsrE13 & Narrowband Hemispheric Irradiance & $\mathrm{W} /\left(\mathrm{m}^{2} \mathrm{~nm}\right)$ & \\
\hline qc_hemisp_narrowband_mfrsrE13 & $\begin{array}{l}\text { Quality check results on field: } \\
\text { Narrowband Hemispheric Irradiance }\end{array}$ & & \\
\hline diffuse_hemisp_broadband_mfrsrE13 & $\begin{array}{l}\text { Diffuse Hemispheric Broadband } \\
\text { Irradiance }\end{array}$ & counts & \\
\hline $\begin{array}{l}\text { qc_diffuse_hemisp_broadband_mfrsrE } \\
13\end{array}$ & $\begin{array}{l}\text { Quality check results on field: Diffuse } \\
\text { Hemispheric Broadband Irradiance }\end{array}$ & & \\
\hline up_hemisp_broadband_mfrTTmC1 & $\begin{array}{l}\text { Broadband Upwelling Hemispheric } \\
\text { Irradiance from TT tower }\end{array}$ & Counts & \\
\hline qc_up_hemisp_broadband_mfrTTC1 & $\begin{array}{l}\text { Quality check results on field: Broadband } \\
\text { Upwelling Hemispheric Irradiance from } \\
\text { TT tower }\end{array}$ & unitless & \\
\hline be_up_hemisp_broadband_mfrTTC1 & $\begin{array}{l}\text { Best-Estimate Broadband Upwelling } \\
\text { Hemispheric Irradiance from TT }\end{array}$ & Counts & $x$ \\
\hline $\begin{array}{l}\text { qc_be_up_hemisp_broadband_mfrTT } \\
\text { C1 }\end{array}$ & $\begin{array}{l}\text { Quality check results on field: Best- } \\
\text { Estimate Broadband Upwelling } \\
\text { Hemispheric Irradlance from TT }\end{array}$ & unitless & $x$ \\
\hline $\begin{array}{l}\text { be_up_hemisp_broadband_status_mfr } \\
\text { TTC1 }\end{array}$ & $\begin{array}{l}\text { Estimation status flag for Best-Estimate } \\
\text { Broadband Upwelling Hemispheric } \\
\text { Irradiance from TT }\end{array}$ & unitless & $x$ \\
\hline up_hemisp_narrowband_mfrTTC1 & $\begin{array}{l}\text { TT Narrowband Upwelling Hemispheric } \\
\text { Irradiance }\end{array}$ & $\mathrm{W} /\left(\mathrm{m}^{2} \mathrm{~nm}\right)$ & \\
\hline qc_up_hemisp_narrowband_mfrTTC1 & $\begin{array}{l}\text { Quality check results on field: TT } \\
\text { Narrowband Upwelling Hemispheric } \\
\text { Irradiance }\end{array}$ & unitless & \\
\hline be_up_hemisp_narrowband_mfrTTC1 & $\begin{array}{l}\text { Best-Estimate TT Narrowband Upwelling } \\
\text { Hemispheric Irradiance }\end{array}$ & $\mathrm{W} /\left(\mathrm{m}^{2} \mathrm{~nm}\right)$ & $x$ \\
\hline $\begin{array}{l}\text { qc_be_up_hemisp_narrowband_mfrTT } \\
\text { C1 }\end{array}$ & $\begin{array}{l}\text { Quality check results on field: Best- } \\
\text { Estimate TT Narrowband Upwelling } \\
\text { Hemispheric Irradiance }\end{array}$ & unitless & $x$ \\
\hline $\begin{array}{l}\text { be_up_hemisp_narrowband_status_mf } \\
\text { rTTC1 }\end{array}$ & $\begin{array}{l}\text { Estimation status flag for Best-Estimate } \\
\text { TT Narrowband Upwelling Hemispheric } \\
\text { Irradiance }\end{array}$ & unitless & $x$ \\
\hline cosine_solar_zenith_angle_mfrTTC1 & $\begin{array}{l}\text { Quality check results on field: Cosine } \\
\text { Solar Zenith Angle from TT }\end{array}$ & unitless & $\mathrm{x}$ \\
\hline $\begin{array}{l}\text { qc_cosine_solar_zenith_angle_mfrTTC } \\
1\end{array}$ & $\begin{array}{l}\text { Quality check results on field: Cosine } \\
\text { Solar Zenith Angle from TT }\end{array}$ & unitless & $x$ \\
\hline
\end{tabular}




\begin{tabular}{|c|c|c|c|}
\hline Fieldname & Description & Units &.$s 1$ \\
\hline down_short_hemisp_beflux1longC1 & $\begin{array}{l}\text { Best estimate of direct + best estimate of } \\
\text { diffuse from SIRSE13, SIRSC1, \& BRS. }\end{array}$ & $\mathrm{W} / \mathrm{m}^{2}$ & $x$ \\
\hline up_short_hemisp_beflux1longC1 & $\begin{array}{l}\text { Upwelling (10 meter) Shortwave } \\
\text { Hemispheric Irradiance }\end{array}$ & $\mathrm{W} / \mathrm{m}^{2}$ & $x$ \\
\hline short_direct_normal_beflux1longC1 & Shortwave Direct Normal Irradiance & $\mathrm{W} / \mathrm{m}^{2}$ & $x$ \\
\hline up_short_hemisp_irt25mC1 & $\begin{array}{l}\text { Upwelling Shortwave Hemispheric } \\
\text { Irradiance, Pyranometer }\end{array}$ & $\mathrm{W} / \mathrm{m} 2$ & $x$ \\
\hline qc_up_short_hemisp_irt25mC1 & $\begin{array}{l}\text { Quality check results on field: Upwelling } \\
\text { Shortwave Hemispheric Irradiance, } \\
\text { Pyranometer }\end{array}$ & unitless & $\mathrm{X}$ \\
\hline hemisp_broadband_mfrsr & $\begin{array}{l}\text { Best Measured Hemispheric Broadband } \\
\text { Irradiance from MFRSRC1 and/or } \\
\text { MFRSRE13 }\end{array}$ & $\mathrm{W} / \mathrm{m}^{2}$ & \\
\hline qc_hemisp_broadband_mfrsr & $\begin{array}{l}\text { Quality check results on field: Best } \\
\text { Measured Hemispheric Broadband } \\
\text { Irradiance from MFRSRC1 and/or } \\
\text { MFRSRE13 }\end{array}$ & unitless & \\
\hline hemisp_broadband_facility_mfrsr & $\begin{array}{l}\text { MFRSR Source of Hemispheric } \\
\text { Broadband Irradiance used in calculating } \\
\text { be_hem } \\
\text { isp_broadband_mfrsr,surface_albedo_m } \\
\text { fr_broadband_10m, and } \\
\text { surface_albedo_mfr_broadband_25m }\end{array}$ & unitless & \\
\hline be_hemisp_broadband_mfrsr & $\begin{array}{l}\text { Best Estimate Best Measured } \\
\text { Hemispheric Broadband Irradiance from } \\
\text { MFRSRC1 and/or } \\
\text { MFRSRE13 }\end{array}$ & $\mathrm{Wm}^{-2}$ & $x$ \\
\hline qc_be_hemisp_broadband_mfrsr & $\begin{array}{l}\text { Quality check results on field: Best } \\
\text { Estimate Best Measured Hemispheric } \\
\text { Broadband Irradiance from } \\
\text { MFRSRC1 and/or MFRSRE13 }\end{array}$ & unitless & $x$ \\
\hline be_hemisp_broadband_status_mfrsr & $\begin{array}{l}\text { Estimation status flag for Best Estimate } \\
\text { Best Measured Hemispheric Broadband } \\
\text { Irradiance from MFRSRC1 and/or } \\
\text { MFRSRE13 }\end{array}$ & unitless & $x$ \\
\hline hemisp_narrowband_mfrsr & $\begin{array}{l}\text { Best Measured Hemispheric } \\
\text { Narrowband Irradiance from MFRSRC1 } \\
\text { and/or MFRSRE13 }\end{array}$ & $\mathrm{Wm}^{-2}$ & \\
\hline qc_hemisp_narrowband_mfrsr & $\begin{array}{l}\text { Quality check results on field: Best } \\
\text { Measured Hemispheric Narrowband } \\
\text { Irradiance from MFRSRC1 and/or } \\
\text { MFRSRE13 }\end{array}$ & unitless & \\
\hline
\end{tabular}




\begin{tabular}{|c|c|c|c|}
\hline Fieldname & Description & Units &.$s 1$ \\
\hline hemisp_narrowband_facility_mfrsr & $\begin{array}{l}\text { MFRSR Source of Hemispheric } \\
\text { Narrowband Irradiance used in } \\
\text { calculating } \\
\text { be_hemisp_narrowband_mfrsr,surface_a } \\
\text { lbedo_mfr_narrowband_10m, and } \\
\text { surface_albedo_mfr_narrowband } 25 \mathrm{~m}\end{array}$ & unitless & \\
\hline be_hemisp_narrowband_mfrsr & $\begin{array}{l}\text { Best Estimate Best Measured } \\
\text { Hemispheric Narrowband Irradiance } \\
\text { from MFRSRC1 and/or MFRSRE13 }\end{array}$ & $\mathrm{Wm}^{-2}$ & $\mathrm{X}$ \\
\hline be_hemisp_narrowband_status_mfrsr & $\begin{array}{l}\text { Estimation status flag for Best Estimate } \\
\text { Best Measured Hemispheric } \\
\text { Narrowband Irradiance from MFRSRC1 } \\
\text { and/or MFRSRE13 }\end{array}$ & unitless & $\mathrm{X}$ \\
\hline surface_albedo_mfr_broadband_TT & MFR Broadband Surface Albedo at TT & unitless & \\
\hline $\begin{array}{l}\text { qc_surface_albedo_mfr_broadband_T } \\
T\end{array}$ & $\begin{array}{l}\text { Quality check results on field: MFR } \\
\text { Broadband Surface Albedo at the TT } \\
\text { tower }\end{array}$ & unitless & \\
\hline $\begin{array}{l}\text { be_surface_albedo_mfr_broadband_T } \\
T\end{array}$ & $\begin{array}{l}\text { Best-Estimate MFR Broadband Surface } \\
\text { Albedo at the TT tower }\end{array}$ & unitless & $\mathrm{X}$ \\
\hline $\begin{array}{l}\text { qc_be_surface_albedo_mfr_broadband } \\
\text { _TT }\end{array}$ & $\begin{array}{l}\text { Quality check results on field: Best } \\
\text { Estimate MFR Broadband Surface } \\
\text { Albedo at TT }\end{array}$ & unitless & $\mathrm{X}$ \\
\hline $\begin{array}{l}\text { be_surface_albedo_mfr_broadband_T } \\
\text { T_status }\end{array}$ & $\begin{array}{l}\text { Estimation status flag for Best Estimate } \\
\text { MFR broadband Surface Albedo at the } \\
\text { TT tower }\end{array}$ & unitless & $\mathrm{X}$ \\
\hline surface_albedo_mfr_narrowband_TT & MFR Narrowband Surface Albedo at TT & unitless & \\
\hline $\begin{array}{l}\text { qc_surface_albedo_mfr_narrowband_T } \\
T\end{array}$ & $\begin{array}{l}\text { Quality check results on field: MFR } \\
\text { Narrowband Surface Albedo at TT }\end{array}$ & unitless & \\
\hline $\begin{array}{l}\text { be_surface_albedo_mfr_narrowband_ } \\
\text { TT }\end{array}$ & $\begin{array}{l}\text { Best Estimate MFR Narrowband Surface } \\
\text { Albedo at TT }\end{array}$ & unitless & $X$ \\
\hline $\begin{array}{l}\text { qc_be_surface_albedo_mfr_narrowban } \\
\text { d_TT }\end{array}$ & $\begin{array}{l}\text { Quality check results on field: Best } \\
\text { Estimate MFR Narrowband Surface } \\
\text { Albedo at TT }\end{array}$ & unitless & $\mathrm{X}$ \\
\hline $\begin{array}{l}\text { be_surface_albedo_mfr_narrowband_ } \\
\text { TT_status }\end{array}$ & $\begin{array}{l}\text { Estimation status flag for Best Estimate } \\
\text { MFR Narrowband Surface Albedo at TT }\end{array}$ & unitless & $\mathrm{X}$ \\
\hline $\begin{array}{l}\text { be_surface_albedo_psp_broadband_T } \\
T\end{array}$ & PSP broadband surface albedo at TT & unitless & $\mathrm{X}$ \\
\hline $\begin{array}{l}\text { qc_be_surface_albedo_psp_broadban } \\
\text { d_TT }\end{array}$ & $\begin{array}{l}\text { "Quality check results on field: PSP } \\
\text { broadband surface albedo at TT }\end{array}$ & unitless & $\mathrm{X}$ \\
\hline broadband_from_spectral_albedo_TT & $\begin{array}{l}\text { Broadband albedo at TT estimated from } \\
\text { integrating spectral albedos weighted by } \\
\text { surface flux calculated from CHARTS }\end{array}$ & unitless & $\mathrm{X}$ \\
\hline $\begin{array}{l}\text { qc_broadband_from_spectral_albedo_ } \\
\text { TT }\end{array}$ & $\begin{array}{l}\text { Quality check results on field: Broadband } \\
\text { albedo at TT estimated from integrating } \\
\text { spectral albedos weighted by surface } \\
\text { flux calculated from CHARTS }\end{array}$ & unitless & $\mathrm{X}$ \\
\hline surface_type_TT_tower & Derived surface type under the TT tower & unitless & $\mathrm{X}$ \\
\hline
\end{tabular}




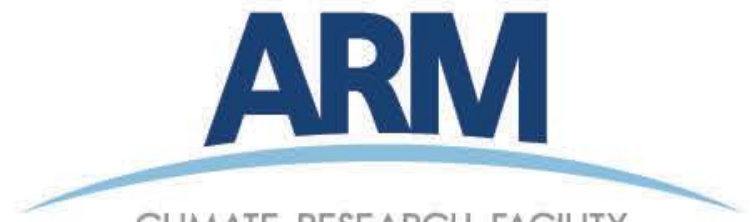

CLIMATE RESEARCH FACILITY

www.arm.gov

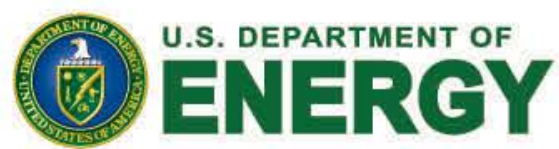

Office of Science 